\title{
LOBBYING, INNOVATION AND PROTECTIONIST CYCLES
}

\author{
Gabriel Sánchez ${ }^{*}$ \\ Department of Economics and Business \\ Universitat Pompeu Fabra
}

February 1998

\footnotetext{
* I am especially grateful to K. Bagwell, A. Casella, R. Findlay, and G. Mondino for their guidance and encouragement. I would also like to thank J. Bhagwati, D. Davis, E. Helpman, P. Lane, R. Miller, R. Perotti, V. Quadrini, D. Rodrik, C. Freund, G. Di Giorgio, A. Khalaf, D. Traca and seminar participants at Columbia U., U. Chicago GSB, Northwestern U. KGSM, U. Wisconsin, U. Pennsylvania, UT-Austin, U. Pompeu Fabra, IIES-Stockholm U., U. Maryland, UC-Irvine, INSEAD, U. San Andres, and U. Di Tella, for their helpful comments and suggestions. The usual disclaimer applies.
} 


\begin{abstract}
$\underline{\text { Abstract }}$
This paper explains why trade liberalizations occur in developing countries, and why they are often reversed. It does so by focusing on the use of lobbying for protection by import competing firms as a means to postpone costly product quality upgrades to keep up with foreign competitors. Given the availability of a political market for import tariffs, domestic firms will lobby for a sequence of tariffs that insulate domestic profits from a widening quality gap, thereby allowing adjustment to be postponed. But as the contributions required by the government grow with the size of the quality gap, it will be optimal to adjust quality and to decrease the lobbying effort at some time, leading to liberalization and technological catch-up. But then the equilibrium tariff will again be small and "cheap", and it will pay to start lobbying anew, until the next quality adjustment. Therefore, cycles in protection will occur as a result of the use of lobbying as a substitute for innovation. The model thus sheds new light on the impact of the costs of protection on the effectiveness of the lobbying effort over time, and on their implications for the timing and the time horizon of trade reforms in developing countries.
\end{abstract}

Keywords: Quality ladders, North-South Trade, Imitation, Endogenous Tariffs, Lobbying, Trade Liberalization, Cycles.

JEL Classification Numbers: F12, F13, O31, D72, D78 


\section{Introduction}

The rush to free-trade by developing countries in the past decade has represented a dramatic turnaround in the trade policy stance adopted by most of these countries, after several decades of pursuing inward-looking strategies. ${ }^{1}$ However, these have not been the first trade reforms attempted by these nations. During the post-War era many of these countries undertook at some point a comprehensive trade liberalization that included a major discrete reduction in barriers to imports of foreign goods. But the high hopes associated with these reforms were quickly erased in most cases, as protectionist pressures ultimately prevailed and closed trade policies were reimplemented. $^{2}$ And while the increasing integration of the world economy seems to hold enormous promise for locking in the recent liberalizations, many of these reforms have already experienced partial reversals that, albeit disguised as measures to countervail balance of payment problems, have been considered to be accommodating domestic demands for protection. ${ }^{3}$ All these episodes suggest the existence of cycles in protection in many developing countries. ${ }^{4}$ Given that interest-group lobbying activity has been pointed out as the main factor behind recurrent protectionism in these economies, it is worth inquiring into the political-economic interactions behind the implementation of trade reforms and into their implications for the time horizon of trade liberalization.

In order to shed light on these issues, I will explore the hypothesis that there is a direct effect of closed trade policies on technological backwardness, that is perceived by policymakers, and which weakens the power of trade lobbyists over time, leading to a liberalization as the technological gap reaches an intolerable level. ${ }^{5}$ This hypothesis is inspired by the series of empirical studies that find that isolation from foreign competition discourages innovation and hurts growth, suggesting that the political 
attitude towards protection will most likely become less favorable over time, as closure imposes increasing costs on society. ${ }^{6}$ A representative sample of these costs of protection is provided by Little et al (1970), who found that for many protected industries in developing countries in the 1960s the value of domestic output at world prices was less than the value of tradable inputs at world prices; i.e., these activities were not viable without protection. An important example is the Indian Ambassador automobile: the original model remained unchanged for 30 years, despite global advances in this industry. ${ }^{7}$ Another good example is the Acindar steel firm in Argentina, whose first plant was built during World War II and kept in operation without major improvements in an isolated environment until 1978, despite having been acknowledged as obsolete fifteen years before that. ${ }^{8}$

The possibility of the occurrence of trade liberalization as a result of the increasing welfare losses from protection will be analyzed here from the point of view of individual firms or industries, in order to draw implications for the occurrence of cycles at the aggregate level. The scenario analyzed is one in which the government makes available a market for protection that is viewed by domestic firms as a means to postpone costly innovation to keep up with foreign competitors. This availability of "protection for sale" is likely to lead to both increasing protection levels and a widening in the technological gap. However, if the cost of lobbying rises with the level of protection, a point may be reached in which innovating and reducing the lobbying effort become more profitable. At this point, "liberalization" and catch-up would take place. But once the adjustment has occurred, lobbying is likely to become cheap again, thus leading to the possibility of a new cycle in protection.

In the model developed here, domestic firms engage in Bertrand competition with foreign producers that are upgrading product quality at a constant and exogenous 
rate. In the absence of innovation, prices and profits will be falling as result of the widening quality gap. Domestic firms must incur a fixed cost to imitate foreign innovations, and hence they do not continuously imitate, but rather define a sequence of intervals during which quality is held constant, followed by a catch-up to foreign quality between intervals. When a market for protection is made available, the firms lobby for sequences of rising tariffs that offset the effect of the widening gap over prices and profits, mitigating the need for adjustment. However, the welfare losses from protection and the associated contributions from lobbying firms required by the government will rise with the size of the tariff. Domestic firms will thus still find it profitable to adjust at intervals of constant duration, and to simultaneously reduce the lobbying effort. At this point, the equilibrium tariff experiences a discrete reduction, and a liberalization ensues, but is followed by a new cycle in protection as the quality gap widens again.

The model thus provides a new insight regarding the time path of trade policies in developing countries. Increasing technological backwardness as a result of endogenous protection is found to be an important determinant of liberalization. By the same token, the catch-up that follows the liberalization is found to facilitate a renewal of protection, by lowering the costs of lobbying. The mechanism analyzed here provides an explanation for the occurrence of cycles at a firm or industry level, but it can be reconciled with the occurrence of aggregate cycles by means of the occurrence of an aggregate shock to the political system, such as the trade reform conditionalities imposed by the multilateral lending organizations in the 1980 s, which would coordinate liberalization and catch-up across the board. The differences across industries would be revealed by the degree of liberalization in each industry, and by the differences in the speed of return to a growing protection path. 
These findings add to the view that trade reforms attain when macroeconomic crises relegate distributional considerations to a second plane, facilitating the reform by agenda-setting technocrats which ascribe as the costs of protection only the traditional static Harberger triangles. ${ }^{9}$ The model also has the interesting feature that it offers a pure political economy explanation for trade liberalization, thus adding to the terms of trade motive proposed by the literature on reciprocal trade liberalization. ${ }^{10}$ Furthermore, the mechanism presented in this model captures the stylized fact that trade liberalization in developing countries tends to occur in a rather abrupt fashion, especially when compared to the time it takes to build up protection. ${ }^{11}$

The vast literature on the political determination of trade policies in a static framework, while providing useful insights, falls short of explaining the time path of protection. ${ }^{12}$ It is thus necessary to develop models of endogenous protection in a dynamic framework, where the trade policies implemented are the result of politicoeconomic equilibria that are changing over time, as suggested by Krueger (1993). The model developed here attempts to fill a small portion of this void. ${ }^{13}$ In this vein, it complements Krueger's view that endogenous protection had increasing costs that contributed to its own demise, but differs in that Krueger proposes that these costs arose mainly from the increasing economic disarray associated to the intricate cobweb of discretionary policies, rather than from a deliberate attempt to postpone costly technological improvements. $^{14}$

This paper closely relates to the literature that explains the occurrence of long cycles of stagnation and growth in a closed economy in terms of the use of political influence by incumbent innovators to prohibit the adoption of new technologies. ${ }^{15}$ It is also connected to the literature that focuses on the repeated use of lobbying to explain the persistence, and eventual termination, of protection to declining industries that 
must undertake costly adjustment in response to a terms of trade shock. ${ }^{16}$ Finally, it is linked as well to the literature that analyzes how technology adoption is delayed by temporary protection, granted until the firm innovates, and how a firm may never innovate and temporary protection may become permanent if the government cannot credibly commit to liberalize trade. ${ }^{17}$ An interesting implication of this strand of literature and this paper is that they suggest that trade policies and productivity growth may both be endogenous variables, as opposed to the usual theoretical and empirical treatment of trade liberalization as exogenous and productivity growth as endogenous.

In Section 2 I present a model of quality adjustment for domestic firms which compete with foreign producers that are continuously updating the quality of their products. In Section 3, I introduce the availability of a political market for endogenous tariffs, and derive the equilibrium tariffs and their time path, and the optimal policy for quality adjustment and lobbying. In Section 4, I suggest a mechanism for the coordination of cycles at the aggregate level. In Section 5, I present the main conclusions, and suggest extensions to this line of research.

\section{A Model of Quality Adjustment}

In this section I analyze the optimal quality adjustment policy for "Southern" firms that engage in Bertrand competition with "Northern" producers that are upgrading product quality at a constant and exogenous rate. The main result of this section is that under the assumption of fixed costs to imitation the optimal policy for domestic firms will be to keep product quality unchanged over intervals of constant duration, and to catch up to foreign quality between intervals. As a result of the widening of the quality gap between Northern and Southern goods, prices and profits will fall continuously within each interval, experiencing discrete increases at the time of 
the imitation. Import tariffs will dampen the effects of a widening gap on prices and profits, allowing to postpone adjustment.

I consider the behavior of producers of differentiated goods in a "Southern" economy. By "Southern" I mean an economy in which domestic firms possess the ability to imitate quality improvements by competitors in the "North," but not to leapfrog them, and that can compete with them by virtue of lower domestic wages. There is a continuum of differentiated "hi-tech" goods indexed by $j \in[0,1]$, with one domestic firm per product line. I do not allow free entry. ${ }^{18}$ Each Southern firm will engage in Bertrand competition for its domestic market with a foreign producer. The domestic and the foreign firms offer goods that are perfect substitutes, and that may differ only in their quality levels. Therefore, the demand for a domestic good will depend both on its price and its quality with respect to the rival foreign good. There is another productive sector that manufactures a homogeneous good that is perfectly tradable in international markets. There exist two types of agents, workers, who are also the consumers, and entrepreneurs who own the firms and do not consume at home. Intertemporal preferences over consumption are defined by:

$$
U_{0}=\int_{0}^{\infty} \log D(t) e^{-\rho t} d t
$$

where $D(t)$ is a consumption index of the differentiated and homogeneous goods, and $\rho$ is the domestic rate of time preference. Instantaneous utility is defined over the consumption index $D(t)$ as in Grossman (1992) by

$$
\log D(t)=s_{x} \int_{0}^{1} \log \left[\sum_{m} q_{m}(j) x_{m t}(j)\right] d j+\left(1-s_{x}\right) \log \left(y_{t}\right)
$$

where $q_{m}(j)=e^{\lambda(j) m}$ represents the quality of $\operatorname{good} j$ after $m$ improvements and $x_{m t}(j)$ denotes consumption of quality $m$ of product type $j$ at time $t ; y_{t}$ denotes the 
consumption of the homogeneous good at time $t ; s_{x}$ denotes the expenditure share on differentiated goods; $\lambda(j)$ represents the size of the innovation in each product line. At any time there will exist several generations (number of quality improvements) for each differentiated good, but in equilibrium, only the goods with the lowest quality-adjusted price will be consumed in each product line, because the goods in each product line are perfect substitutes. Given the wage differential between North and South there will be only one producer in the market in each period. I choose units so that the lowest quality of each product (the one available at time $\tau=0$ ) offers one unit of service; i.e., $q_{0}(j)=1$. As in Grossman (1990), solving (1) and (2) subject to the corresponding static and dynamic budget constraints, yields the following demand functions, where nominal expenditures have been chosen as the numeraire: ${ }^{19}$

$$
x_{t}(j)=\frac{s_{x}}{p_{t}(j)} \quad \text { (4) } y_{t}=\frac{1-s_{x}}{p_{t}^{y}}
$$

where $x_{t}(j)$ is the quantity demanded at a price $p_{t}(j)$ of the good that has the lowest quality-adjusted price within the product line $j$, and $y_{t}$ is the quantity demanded of the homogenous good at a price $p_{t}^{y}$. The only factor employed in the production of all goods is unskilled labor. Technologies for the production of differentiated goods exhibit constant returns to scale, and are assumed to be identical across all qualities $q$, $x^{i}(j)=\gamma^{i}(j) l_{x}^{i}(j), i=S, N$, where $l_{x}^{i}(j)$ is the amount of labor employed in the product line $j$ in region $i$, and $\gamma^{i}(j)$ its marginal productivity in each product line. The production function of the homogeneous good also displays constant returns to scale, $y=c l_{y}$, where $c$ is the productivity of labor $l_{y}$ employed in this sector in the South. Under these assumptions, domestic wages will be determined as the marginal value 
product of labor in the $y$ sector, whose price $p_{y}^{f}$ is determined in international markets and is assumed to be constant,

$$
p_{y}=p_{y}^{f} \quad \text { (6) } \quad w=c p_{y}^{f}
$$

It is assumed that wages are lower in the South than in the North, in a magnitude such that for all production technologies unit costs are lower in the South. ${ }^{20}$ I assume that the aggregate supply of labor is large enough to ensure a positive supply of the homogeneous good, so that domestic wages remain constant.

Given all these preliminaries, attention is now turned to the determination of the outcomes of Bertrand competition in the domestic market between the domestic producer in each product line and its Northern competitors. Since there is no free entry and wages are constant, the problem will be symmetric to all firms, and I can thus focus on the behavior of a representative firm and drop the $j$ subscript, and assume for ease of notation that $\gamma^{s}=\gamma^{v}=1$. Bertrand competitors will engage into limit pricing: given demand functions with unit price elasticities, domestic firms will price at (a shade below) the marginal cost of the foreign rival, $w^{N}$, adjusted by relative quality. To see this, let domestic quality be $q_{t}$ and relative quality be $z_{t}=q_{t} / q_{t}^{N}$. Since the minimum quality-adjusted price that the foreign producer can charge is $w^{N} / q_{t}^{N}$, the domestic producer will charge a price

$$
p\left(z_{t}\right)=z_{t} w^{N}
$$

such that it offers a lower quality-adjusted price. ${ }^{21}$ The profits obtained by the Southern firm will thus be a function of the relative quality, $z_{t}$. The higher the quality gap, the lower the price, and the lower the profits,

$$
F\left(z_{t}\right)=s_{x}\left[1-w / z_{t} w^{N}\right] \quad F^{\prime}>0, F^{\prime \prime}<0
$$


where $F($.$) denotes profits.$

Having determined the outcome of the Bertrand competition in each product line as a function of the quality gap between the Northern and Southern goods, we can now focus attention on the determinants of this gap. The quality of the representative foreign good is growing at a constant given rate $\lambda$ per unit of time that is perfectly anticipated by the domestic firms. If the initial foreign quality level is $q_{0}^{N}=1$, the quality level at time $t$ is $q_{t}^{N}=e^{\lambda t} \cdot{ }^{22} \mathrm{I}$ assume that the representative Southern firm can imitate the quality of the state-of-the-art good developed in the North by incurring a fixed real cost $\beta$, which is independent of the size of the quality gap. This is an important assumption, which can be motivated by the verified importance of fixed costs in the adoption of foreign technology in developing countries. ${ }^{23}$ As a consequence of the fixed costs to imitation, the optimal adjustment policy is characterized by a sequence of intervals during which domestic quality is held constant, followed by discrete quality adjustments. ${ }^{24}$ The Southern firm will solve this problem in the following fashion. Suppose at $t_{0}=0$ the firm plans to adjust its quality at the points of time $0 \leq t_{1}<t_{2}<t_{3}<\ldots<t_{\tau}<\ldots$. Respectively denote the fixed domestic quality and the relative quality in the interval $\left[t_{\tau}, t_{\tau+l}\right)$ by $q_{\tau}$ and $q_{\tau} e^{-\lambda t}$. Profits during this interval, including the adjustment costs at time $t_{\tau+1}$, are given by:

$$
\int_{t_{\tau}}^{t_{\tau+1}} F\left(q_{\tau} e^{-\lambda t}\right) e^{-\rho t} d t-\beta e^{-\rho t_{\tau+1}}
$$

Long run profits are obtained by summing (9) over $\tau$ :

$$
V_{0}=\sum_{\tau=0}^{\infty}\left[\int_{t_{\tau}}^{t_{\tau+1}} F\left[q_{\tau} e^{-\lambda t}\right] e^{-\rho t} d t-\beta e^{-\rho t_{\tau+1}}\right]
$$

where initial quality is assumed to be $q_{0}=1$, and $t_{0}=0$. The firm's objective will be to choose sequences $\left\{t_{\tau}\right\},\left\{q_{\tau}\right\}, \tau=1,2, \ldots$ that maximize $V_{0}$, subject to $q_{\tau} \leq e^{\lambda t_{\tau}}$. The 
solution to this problem is presented in Appendix B, available upon request. Since profits grow monotonously on domestic quality and the cost of imitation does not depend on the size of the quality gap, the Southern firm will always catch up with the latest quality developed in the North, and thus,

$$
q_{\tau}=e^{\lambda t_{\tau}}
$$

The optimal timing to imitate is given by the first order condition with respect to $t_{\tau}$,

$$
F\left[q_{\tau} e^{-\lambda t_{\tau}}\right]=F\left[q_{\tau-1} e^{-\lambda t_{\tau}}\right]+\rho \beta+\mu_{\tau} \lambda e^{\lambda t_{\tau}}
$$

which states that the gains from postponing imitation, given by the interest saved on the imitation costs, $\rho \beta$, plus the effect of a higher $t_{\tau}$ on the marginal return from relaxing the quality constraint, $\mu_{\tau} \lambda_{e^{\lambda t}}^{\lambda}$, must equate the loss from the postponement, given by the increase in profits after the imitation, $F\left[q_{\tau} e^{-\lambda t}{ }_{\tau}\right]-F\left[q_{\tau-l} e^{-\lambda t}\right]$.

Proposition 1. The firm will define a sequence of intervals during which domestic quality is held constant, catching up to foreign quality between intervals. The length of these intervals, $\left\{t_{\tau^{-}} t_{\tau-l}\right\}$, denoted by $\varepsilon$, will be constant and unique, and implicitly determined by:

$$
\left[e^{\lambda \varepsilon}-1\right]-\frac{\lambda}{\lambda-\rho}\left[e^{(\lambda-\rho) \varepsilon}-1\right]=\frac{w^{N}}{s_{x} w} \rho \beta
$$

The proof is provided in Appendix B, available upon request. It entails showing that because of the recursive nature of the problem, if $\left\{t_{\tau}{ }^{*}\right\},\left\{q_{\tau}{ }^{*}\right\}$, maximize $V_{0}$, by the principle of optimality they also maximize the present discounted value of profits at $t_{1}{ }^{*}$, $t_{2}{ }^{*}, \ldots$, and so on, denoted by $V_{l}, V_{2}, \ldots$ Therefore, in the presence of fixed costs to imitation and of constant foreign quality upgrading, the firm will choose to adjust its quality at intervals of finite length $\varepsilon .^{25}$ The duration of these intervals will increase with a decrease in $w / w^{N}$, as the ensuing increase in profits at all levels of the quality gap 
allows to postpone adjustment. It will also increase with the cost of adjustment, $\beta$. Finally, the effect of an increase in $\lambda$ will be ambiguous, as faster foreign quality growth will increase the marginal return from relaxing the quality constraint, but it will also decrease prices and profits at all times.

Under this optimal policy, the relative quality $z_{t}$ will fluctuate between two fixed bounds, $z_{\max }=1$ and $z_{\min }=e^{-\lambda \varepsilon}$, decreasing continuously over each interval. Correspondingly, the prices will fluctuate between $p(1)=w^{N}$ and $p\left(e^{-\lambda \varepsilon}\right)=w^{v} e^{-\lambda \varepsilon}$, with profits falling from $F(1)=s_{x}\left[1-\mathrm{w} / w^{N}\right]$ to $F\left(e^{-\lambda \varepsilon}\right)=s_{x}\left[1-\mathrm{w} / w^{N} e^{-\lambda \varepsilon}\right]$ (See Figure 1). The consumption index $D(t)$ will be growing over time because of the decline of prices within each interval, and because of the imitations between intervals. ${ }^{26}$

Let us now consider the implications of implementing tariffs on the imports of foreign differentiated goods. A tariff will raise the limit price: domestic firms can price now at the foreign producer's marginal cost adjusted for relative quality and for the tariff, i.e.,

$$
p_{t}\left(z_{t}, 1+\delta_{t}\right)=w^{N}\left(1+\delta_{t}\right) z_{t}
$$

where $\delta_{t}$ is an ad-valorem tariff. Tariffs will thus have a positive impact on profits,

$$
F\left[z_{t}\left(1+\delta_{t}\right)\right]=s_{x}\left[1-w / z_{t} w^{N}\left(1+\delta_{t}\right)\right] \quad \partial F(.) / \partial\left(1+\delta_{t}\right)>0
$$

What will be the effect on the policy for imitation? Tariffs will increase the wedge between the tariff adjusted foreign and domestic marginal costs of production, thereby allowing domestic firms to postpone imitation. In particular, a sequence of tariffs $\left\{1+\delta_{t}\right\}$ such that $\left(1+\delta_{t}\right) \geq \mathrm{w} / z_{t} w^{w}$, would allow the domestic the firm to postpone adjustment indefinitely, by isolating domestic prices from the widening quality gap. On the other hand, a permanent tariff would also allow the Southern firm to postpone 
imitation, but not indefinitely, since domestic prices would still decline continuously in response to the widening quality gap in each interval.

\section{Endogenous Tariff Cycles}

I now consider the implications of the availability of a political market for import tariffs. Each firm will act as a profit maximizer, and will lobby for its own tariff, since the other firms' tariffs will not affect its profits. ${ }^{27}$ The problem is symmetric to all firms, and I can thus focus on the behavior of a representative firm. The equilibrium tariff will result from a contribution game between the firm and the government, a dynamic analogue of Grossman and Helpman (1994). ${ }^{28}$ At each time the firm will confront the government with a contribution schedule for different tariffs, chosen optimally in anticipation of the politician's response, given the quality gap at that instant. The government will then choose the tariff that maximizes its own welfare at that time. ${ }^{29}$ The firm will seek tariffs that dampen the effect of a growing quality gap on profits, allowing adjustment to be postponed. However, the required contributions are likely to be growing as the gap widens, eroding the benefits from lobbying without adjusting. Therefore, it is in order to inquire if the firm will choose to lobby for a sequence of tariffs that allow it to delay imitation indefinitely, or if it will prefer to adjust at regular intervals. It is also necessary to determine if the firm will lobby for protection at all the levels of the quality gap, or only after a certain threshold has been reached.

The main results of this section can be briefly summarized. There will be cycles in protection. The optimal policy for the domestic firm will be to lobby for a sequence of tariffs that exactly offset the negative effects of a widening quality gap on prices and profits. However, since the campaign contributions required by the government will be 
growing with the size of the tariffs, it will still be optimal to imitate foreign quality at intervals of constant duration, and to lobby for a lower tariff or to cease lobbying when quality is adjusted. When political preferences for contributions are relatively low, there will occur a full liberalization, and free trade will prevail temporarily. During these "good times" the firm will contribute positively to growth via the decline in domestic prices. However, once the quality gap has reached a certain threshold, it will be profitable to start lobbying again, until the next quality adjustment. When the preferences for contributions are relatively high, the firm will never cease to lobby. At the time of the adjustment, the tariff will fall, but not to zero. There will thus be a partial liberalization, with tariffs starting to grow again immediately thereafter. In this case, the "good times" will last just one instant, when the imitation occurs.

The firm's problem will now be to define an optimal policy for imitation, the contributions that it will propose to the government in exchange for a tariff, and whether it will lobby during the entire interval between imitations, or during only part of it. Due to the discrete nature of the quality adjustment and the continuous nature of the tariff determination, the firm will first solve the policies for imitation and for the initiation of lobbying as a function of the equilibrium tariffs and contributions, and it will then engage in a contribution game with the government, which will determine tariffs and contributions at each time.

The firm will solve its dynamic optimization problem in the same fashion as before. Suppose at $t_{0}=0$ the firm plans to adjust its quality at the points of time $0 \leq t_{1}<t_{2}<t_{3}<\ldots<t_{\tau}<\ldots$. Further suppose that the firm plans to lobby during all or part of each interval between adjustments, starting at times $T_{0} \leq T_{1}<T_{2}<T_{3}<\ldots<T_{\tau}<\ldots, T_{\tau} \in\left[t_{\tau}\right.$, 
$\left.t_{\tau+1}\right]$. Denote the tariffs within the interval by $\left(1+\delta_{t-t_{\tau}}\right)$. The profits during this interval are given by:

$$
\begin{aligned}
& \int_{t_{\tau}}^{T_{\tau}} F\left[q_{\tau} e^{-\lambda t}\right] e^{-\rho t} d t+\int_{T_{\tau}}^{t_{\tau+1}} F\left[q_{\tau} e^{-\lambda t}\left(1+\delta_{t-t_{\tau}}\right)\right] e^{-\rho t} d t \\
& -\beta e^{-\rho t_{\tau+1}}-\int_{T_{\tau}}^{t_{\tau+1}} g\left(1+\delta_{t-t_{\tau}}\right) e^{-\rho t} d t
\end{aligned}
$$

where $g\left(1+\delta_{t-t_{\tau}}\right)$ represents the campaign contributions to the government as a function of the tariff, i.e., the variable costs of lobbying. The first term corresponds to the profits attained during the initial free trade phase, when prices are falling in response to the widening gap. The second term represents the profits during the subsequent phase at which the firm lobbies for protection, and the behavior of prices depends on the size of the tariff with respect to the quality gap. Finally, the third term corresponds to the contributions that the firm has to pay in exchange for the tariffs. Long run profits are obtained by summing (16) over $\tau$ :

$$
\begin{aligned}
V_{0}=\sum_{\tau=0}^{\infty} & {\left[\int_{t_{\tau}}^{T_{\tau}} F\left[q_{\tau} e^{-\lambda t}\right] e^{-\rho t} d t+\int_{T_{\tau}}^{t_{\tau+1}} F\left[q_{\tau} e^{-\lambda t}\left(1+\delta_{t-t_{\tau}}\right)\right] e^{-\rho t} d t\right.} \\
& \left.-\beta e^{-\rho t_{\tau+1}}-\int_{T_{\tau}}^{t_{\tau+1}} g\left(1+\delta_{t-t_{\tau}}\right) e^{-\rho t} d t\right]
\end{aligned}
$$

The firm's objective will now be to choose sequences $\left\{t_{\tau}\right\},\left\{T_{\tau}\right\},\left\{q_{\tau}\right\}, \tau=1,2, \ldots$ that maximize $V_{0}$, subject to $q_{\tau} \leq e^{\lambda t \tau}$, taking as given $\left\{1+\delta_{t-t_{\tau}}\right\}$ and $\left\{g\left(1+\delta_{t-t_{\tau}}\right)\right\}$. The solution to this problem is presented in Appendix A. Again, it will be optimal for the domestic firm to catch up to the state-of-the-art quality when it innovates,

(11') $\quad q_{\tau}=e^{\lambda t_{\tau}}$ 
The firm will again define a sequence of intervals $\left\{t_{\tau+1}-t_{\tau}\right\}$ during which quality will be held constant, followed by catch-ups to foreign quality. The length of these intervals will be determined by the first order condition with respect to $t_{\tau}$,

$$
F\left[q_{\tau} e^{-\lambda t_{\tau}}\right]-F\left[q_{\tau-1} e^{-\lambda t_{\tau}}\left(1+\delta_{t_{\tau}-t_{\tau-1}}\right)\right]+g\left(1+\delta_{t_{\tau}-t_{\tau-1}}\right)-\rho \beta=\mu_{\tau} \lambda e^{\lambda t_{\tau}}
$$

where the gains from postponing adjustment are as before, while the loss from postponing is now given by $F\left[q_{\tau} e^{-\lambda t_{\tau}}\right]-\left\{F\left[q_{\tau-1} e^{-\lambda t_{\tau}}\left(1+\delta_{t_{\tau}-t_{\tau-1}}\right)\right]-g\left(1+\delta_{t_{\tau}-t_{\tau-1}}\right)\right\}$.

The firm will also have to decide on whether it is going to lobby for protection during all or only part of the interval between imitations, depending on the benefits from lobbying relative to profits under free trade. The firm will thus define a sequence of sub-intervals during which it does not lobby and free trade prevails, the duration of which will be determined by the first order condition with respect to $T_{\tau}$,

$$
F\left[q_{\tau} e^{-\lambda T_{\tau}}\right]=F\left[q_{\tau} e^{-\lambda T_{\tau}}\left(1+\delta_{T_{\tau}-t_{\tau}}\right)\right]-g\left(1+\delta_{T_{\tau}-t_{\tau}}\right)
$$

which states that the loss from switching to lobbying, given by the profits just before the switch, the left hand side of (19), must be equal to the gain, given by the profits just after the switch, the right hand side of (19).

From both (18) and (19) it emerges that both the length of the intervals between adjustments and of the sub-intervals where free trade prevails will be a function of the tariffs and the contribution schedules that result from the equilibrium of the contribution game between the firm and the government. Therefore, it is now in order to determine the equilibrium outcomes of the campaign contributions game.

In this game, the firm first chooses at each time the contribution schedule in anticipation of the government's response, and the politician then selects a tariff that maximizes its own welfare. I further assume that there exists some commitment technology to ensure the payment of the contribution. Both the firm and the 
government are assumed to follow Markovian strategies. ${ }^{30}$ With this structure of moves and the Markovian strategies, the government's choice of tariffs affects only the contemporaneous levels of the contribution and does not affect the quality gap. The politician will thus face a static optimization problem. I assume that the government's instantaneous utility function is given by

$$
\Omega_{t}=\frac{1}{a}\left\{\log D\left(1+\delta_{t-t_{\tau}}\right)+F\left[q_{\tau} e^{-\lambda t}\left(1+\delta_{t-t_{\tau}}\right)\right]\right\}+g\left(1+\delta_{t-t_{\tau}}\right)
$$

The politician seeks to maximize contributions (the term outside braces), but is concerned with the dissatisfaction that tariffs may generate on economic agents, as measured by their effect on consumer and producer surpluses (the terms inside braces), weighted by a parameter $1 / a$. The parameter $a$ can be interpreted as the government's preference for contributions. This objective function is standard in campaign contribution games, and is consistent with the view of a predatory government as the general underlying characteristic of third world states. ${ }^{31}$

Given the contribution schedule offered by the lobby, the politician will implement the tariff that maximizes its own welfare. Its optimization over the tariff choice will yield the following first order condition:

$$
\frac{\partial \log D\left(1+\delta_{t-t_{\tau}}\right)}{\partial\left(1+\delta_{t-t_{\tau}}\right)}+\frac{\partial F\left[q_{\tau} e^{-\lambda t}\left(1+\delta_{t-t_{\tau}}\right)\right]}{\partial\left(1+\delta_{t-t_{\tau}}\right)}=a g^{\prime}\left(1+\delta_{t-t_{\tau}}\right)
$$

The government will require contributions that compensate in the margin the welfare losses arising from the implementation of the tariff. The equilibrium of the game additionally requires that the tariff implemented jointly maximizes government's welfare and the firm's profits ${ }^{32}$ :

$$
\left(1+\delta_{t-t_{\tau}}\right)=\underset{1+\delta_{t-t_{\tau}}}{\arg \max } \frac{1}{a}\left\{\log D\left(1+\delta_{t-t_{\tau}}\right)+F\left[q_{\tau} e^{-\lambda t}\left(1+\delta_{t-t_{\tau}}\right)\right]\right\}+V_{0}
$$


yielding,

$$
\left(1+\delta_{t-t_{\tau}}\right)=\frac{(1+a) w e^{\lambda\left(t-t_{\tau}\right)}}{w^{N}} \quad t \in\left[t_{\tau}, t_{\tau+1}\right)
$$

The equilibrium tariff will increase with the preference for campaign contributions and it will fully insulate prices and profits from increases in the quality gap, and from losses of competitiveness. ${ }^{33}$

Having determined the equilibrium tariffs, it is now in order to determine the contribution schedule, which is derived by integrating (21) over $\left(1+\delta_{t-t_{\tau}}\right)$,

$$
g\left(1+\delta_{t-t_{\tau}}\right)=\frac{s_{x}}{a}\left\{\log \left(1+\delta_{t-t_{\tau}}\right)+\frac{w e^{\lambda\left(t-t_{\tau}\right)}}{w^{N}}\left[\frac{1}{\left(1+\delta_{t-t_{\tau}}\right)}-1\right]\right\}
$$

The contributions required to induce the government to grant the tariff will have to compensate it for the deadweight losses induced by the tariff, given by the loss of consumer surplus (the first term between braces), minus the increases in producer surplus, (the second term between braces). Contributions will increase with the the tariff and with the share of expenditure allocated to differentiated goods, $s_{x}$, and will decline with the preference for campaign contributions. Since the equilibrium tariffs will be increasing over time, the associated contributions will also do so. ${ }^{34}$

It is now possible to determine the lengths of the intervals without protection and without adjustment. Regarding the former, the firm may find that for initially low levels of the quality gap it is not profitable to lobby. However, as the quality gap becomes larger, reducing profits under free trade, it may become profitable to start lobbying at some time. ${ }^{35}$ Now recall that from (19) the firm's optimal policy will be to start lobbying at the time when the profits attained just before starting to lobby equal the net benefits from lobbying at that level of the quality gap. 
Proposition 2. The length of the sub-interval during which the firm does not lobby after it has adjusted quality, $\left\{T_{\tau}-t_{\tau}\right\}$, denoted by $\varepsilon_{o}$, will be unique, and defined by:

$$
\varepsilon_{o}=(1 / \lambda) \log \left[w^{N} /(1+a) w\right]
$$

Proof: See Appendix A. At this time, the equilibrium tariffs and contributions start to grow smoothly from zero. It is straightforward to show that bigger preferences for contributions lead to higher tariffs and net benefits from lobbying, and to a faster the abandonment of free trade. Lower competitiveness yields lower profits under free trade, and induces an earlier beginning of lobbying. A higher rate of growth of foreign quality results in lower profits both under free trade and under lobbying, but the first effect prevails, leading to a shorter free trade period. For values of $(1+a)$ above the relative costs of production $\left(w^{w} / w\right)$ it will be profitable to lobby all the time, even when the firm has adjusted domestic quality.

The next matter of interest is to determine the length of the intervals between imitations. Will the firm be able to postpone adjustment indefinitely? Or will it prefer to imitate at periodic intervals, and to reduce the lobbying effort at that time, leading to an "endogenous liberalization" through a discrete fall in the equilibrium tariff? Two cases will be distinguished. First, the case in which preferences for contributions are low enough to allow for an initial period of temporary free trade. Second, the case in which preferences for contributions are so high that it pays to lobby permanently.

Proposition 3. When the preferences for contributions are such that it is convenient to allow for a temporary free trade after the quality adjustment, the length of the interval between quality adjustments, $\left\{t_{\tau+1}-t_{\tau}\right\}$, denoted by $\varepsilon$, will be unique, and implicitly defined by: 


$$
\begin{gathered}
\frac{1}{(1+a)}-\frac{w}{w^{N}}-\frac{\rho \beta}{s_{x}}+\frac{1}{a}\left[\log \left[\frac{(1+a) w e^{\lambda \varepsilon}}{w^{N}}\right]+\frac{1}{1+a}-\frac{w e^{\lambda \varepsilon}}{w^{N}}\right]= \\
\frac{\lambda}{(\lambda-\rho)} \frac{w}{w^{N}}\left[e^{(\lambda-\rho) \varepsilon_{o}}-1\right]-\frac{\lambda}{(1+a) \rho}\left[e^{-\rho \varepsilon}-e^{-\rho \varepsilon_{o}}\right]
\end{gathered}
$$

Proof: See Appendix A. There will be a cycle in product quality and in protection because the profits after contributions are falling as the quality gap widens. This decline in net benefits from lobbying occurs because profits remain constant under protection, while the contributions are increasing. Since the costs of imitation are not growing over time and the marginal return from relaxing the quality constraint by postponing imitation is converging smoothly to zero, a point will be reached at which it pays to the firm to imitate and to stop lobbying. The increase in profits through a reduction in contributions as result of the quality adjustment justifies incurring the cost of imitation. ${ }^{36}{ }^{37}$ As shown in Appendix A, the length of this interval will increase with increases in $a$, because of higher benefits from lobbying through higher tariffs and lower contributions. Additionally, the duration of this interval will increase with $\beta$. Changes in competitiveness and in $\lambda$ will have an ambiguous effect. ${ }^{38}$

Corollary. The duration of the protectionist phase, $\left\{t_{\tau+1}-T_{\tau}\right\}$, denoted by $\varepsilon_{c}=\varepsilon-\varepsilon_{o}$, will also be unique.

A higher $a$ will increase the length of the protectionist phase, as the higher benefits from lobbying lead to a faster abandonment of free trade and to a postponement of the imitation. The length of this phase will also increase with the cost of imitation. Changes in $\lambda$ and in competitiveness will have an ambiguous effect. ${ }^{39}$

Proposition 4. When the preferences for contributions are so high that lobbying never ceases, $(1+a) w \geq w^{N}$ the length of the interval without adjustment, denoted by $\varepsilon$, will still be unique and implicitly defined by: 


$$
\frac{1}{a}\left[\lambda \varepsilon+\frac{w}{w^{N}}\left(1-e^{\lambda \varepsilon}\right)\right]-\frac{\rho \beta}{s_{x}}=\frac{\lambda}{(1+a) \rho}\left[1-e^{-\rho \varepsilon}\right]
$$

Proof: See Appendix A. ${ }^{40}$ As in the previous case, increases in $a$ and in $\beta$ will delay adjustment and the switching to lower tariffs. In this case, however, a loss of competitiveness will lead to faster imitation and liberalization. The larger the domestic costs of production with respect to the North are, the larger will be the positive effect of tariffs on profits at low levels of the quality gap relative to the positive effect on profits at higher levels of this gap. This means that a loss of competitiveness will lead to a larger reduction in contributions at low levels of the quality gap, thus resulting in an increase in the gains from adjusting and prompting a faster imitation. Changes in $\lambda$ will have an ambiguous effect. ${ }^{41}$ (see Appendix A).

\subsection{Time Path of Quality, Tariffs, Prices, and Operating Profits}

Given the optimal policy for imitation, the relative quality will fluctuate between two fixed bounds, $z_{\max }=1$ and $z_{\min }=e^{-\lambda \varepsilon}$, decreasing continuously over each interval, and jumping upward at the time of the imitation. In the case of permanent lobbying, tariffs will grow continuously between two fixed bounds, $1+\delta_{0}=(1+a) w / w^{N}$ and $1+\delta_{0}=(1+a) w e^{-\lambda \varepsilon} / w^{N}$, jumping downward when imitation attains. As a result, prices and profits will never change, $p(1)=p\left(e^{-\lambda \varepsilon}\right)=(1+a) w, F(1)=F\left(e^{-\lambda \varepsilon}\right)=s_{x}[1-1 /(1+a)]$ (see Figure 2). In the case of full liberalization and temporary free trade, tariffs will be zero until the time of switching to lobbying and will grow continuously thereafter until the next imitation, $1+\delta_{\varepsilon}=(1+a) w e^{\lambda \varepsilon} / w^{N}$. Prices and profits will be constant under lobbying, $p\left(e^{-\lambda \varepsilon_{0}}\right)=p\left(e^{-\lambda \varepsilon}\right)=(1+a) w, F\left(e^{-\lambda \varepsilon_{0}}\right)=F\left(e^{-\lambda \varepsilon}\right)=s_{x}[1-1 /(1+a)]$, will suffer a discrete fall at the time of imitation and liberalization, $p(1)=w^{v}, \quad F(1)=s_{x}\left[1-w / w^{v}\right]$, and will decline continuously thereafter, until the new protectionist phase starts (see Figure 3). 
When free trade initially prevails, the firm's contribution to growth of the consumption index will be positive, as domestic prices decline in response to the widening quality gap. This contribution will be nil during the protectionist phase, as tariffs offset the increasing gap. Finally, the contribution to growth will experience a discrete increase at the time of the imitation. ${ }^{42}$ When permanent lobbying is optimal, the contribution to growth will be nil during the interval without adjustment. However, this contribution will be positive at the time of the imitation, as the quality adjusted price experiences a discrete fall. ${ }^{43}$

\section{Coordinated cycles}

The mechanism analyzed here provides an explanation for the occurrence of cycles at a firm or industry level. The cycles would be exactly simultaneous only if all the industries were technologically identical, with the same relative costs of production, the same costs of imitation, the same foreign quality rate of growth, and they all started at the same point in time. In this sense, the main point of the paper is to analyze how the increasing welfare costs of protection arising from the associated technological backwardness negatively affect the effectiveness of the lobbying effort over time, i.e., how they facilitate liberalization. Additionally, it seeks to shed light on the incentives to re-start lobbying after a liberalization.

Nevertheless, the predictions of this model can be reconciled with the occurrence of cycles at an aggregate level under a series of reasonable assumptions that have historical support. If the outset of World War II were taken as a starting point for most industries, the model would predict that after a period of increasing levels of protection and backwardness, a sequence of liberalizations at the industrylevel would attain, and that their distribution over time would depend on the 
distribution of the technological characteristics across different industries. However, trade liberalizations have usually occurred simultaneously with the implementation of stabilization programs supported by multilateral lending organizations that included trade reform conditionalities. Such developments could be captured by the model in the form of a negative shock to the preferences for contributions, that coordinates the liberalizations across industries, leading to a simultaneous technological catch-up. The differences across industries would be revealed by the degree of liberalization in each industry, and by the speed of return to a growing protection path. Those industries that face higher relative costs of production and/or faster foreign technological upgrading would have higher tariffs following a liberalization, and would also be the ones that return more quickly to lobbying for protection, a fact that has been observed in many of these reforms. ${ }^{44} 45$

Reliance on these exogenous shocks as a coordination device has the disadvantage of apparently suggesting macroeconomic crisis as the determinant of trade liberalization, as in Rodrik (1994). However, the model presented here is identified with respect to the latter by its prediction of a progressive return to growing protection and technological stagnation, at different speeds per industry, as it has been observed in the previous experiences of temporary trade liberalization and the recent episodes of partial reversal to protectionism. Macroeconomic crisis operates here only as a coordination devise, not as a determinant of liberalization.

\section{Conclusions and extensions}

The main contribution of the paper is to show how the increasing welfare costs of protection arising from technological backwardness reduce the effectiveness of the lobbying effort over time, thus facilitating liberalization. Additionally, it seeks to show 
the incentives to re-start lobbying after a liberalization and catch-up. The model shows that if a market for protection is made available, firms that must costly imitate foreign technology to keep up with foreign competitors will find it optimal to lobby for a sequence of tariffs that insulate domestic prices and profits from foreign innovations. Such a behavior will lead to persistent protection, and to a widening technology gap. However, if the government is factoring in the increasing welfare losses of protection, it will require increasing lobbying efforts to maintain protection, and a point will be reached in which domestic firms will prefer to adjust and to allow for a trade liberalization. But now that the firm has caught up with foreign technology, the tariffs needed to offset new foreign innovations are again small and politically inexpensive, and it thus pays to start lobbying again, leading to a cycle in protection. While the model generates the prediction of cycles at the firm or industry level, it can be easily reconciled with the occurrence of cycles at the aggregate level using a series of reasonable assumptions that have historical support.

The model offers some interesting insights about the dynamics of protection in developing countries. The previous episodes of transitory trade liberalization fit nicely into the predictions of the model, as these nations experienced lackluster growth before the liberalization and after the reversal, and high growth during the open period. The main reasons cited for the reversals, namely political and ideological shifts, are also consistent with the mechanisms presented here. The predictions of the model are also consistent with the observed links between protectionism and technological backwardness, and with the productivity gains following large liberalizations. An important implication of this model, shared with the literature on contingent protection and innovation, is that it raises the possibility that trade policies and the associated productivity performance be both endogenous variables, as opposed to most 
theoretical and empirical approaches that treat trade liberalization as exogenous and productivity growth as endogenous. As for the recent liberalizations en masse, the model would have to rely on the trade reform conditionalities imposed by multilateral lending organizations following the debt crisis of the early 1980s as a shock to the effectiveness of lobbying, that abruptly shortened the protectionist cycle across industries in most developing nations. However, the partial reversals in the recent reforms can be explained by the model as the beginning of a new protectionist cycle in industries in countries where the political preferences for contributions from lobbies and/or production costs are relatively high.

One interesting extension to the analysis done here would be to generate an endogenous coordination of cycles. One scenario worth studying is one in which goods have a higher elasticity of substitution in consumption, which could introduce complementarity in the lobbying activities by different firms. In this case, an increase in protection for one good would increase demand for other industries' goods, which could enhance the profitability of lobbying in these industries, thus leading to the possibility of endogenously coordinated cycles. Another scenario worth studying is one in which the high-tech firms produce import-competing intermediate inputs, and in which the other domestic productive sectors that demand these inputs lobby against protection. This extension may yield the result of the attainment of permanent free trade following a first protectionist phase, if the discrete transfer of resources to the producer of final goods following a trade liberalization helps it to countervail the lobbying effort by the import competing firms. 
Figure 1: Profits and timing of imitation under free trade

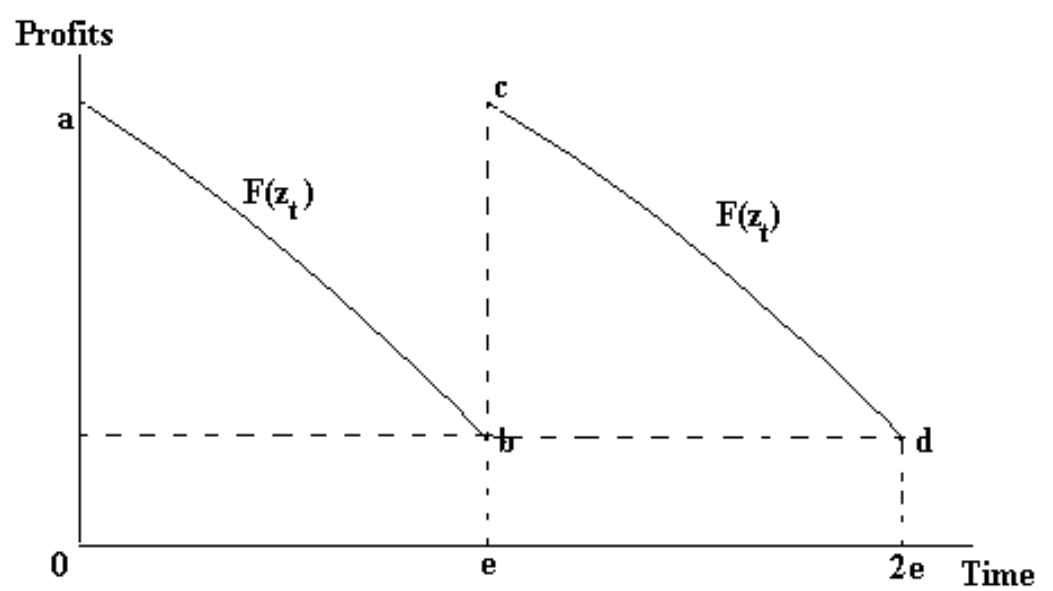

$F\left(z_{t}\right)$ : Profits; b-c: Opportunity cost of imitation; $z_{t}$ : inverse of quality gap $\mathrm{e}, 2 \mathrm{e}$ : Timings of imitation

Figure 2: Time path of profits and timing of imitation and

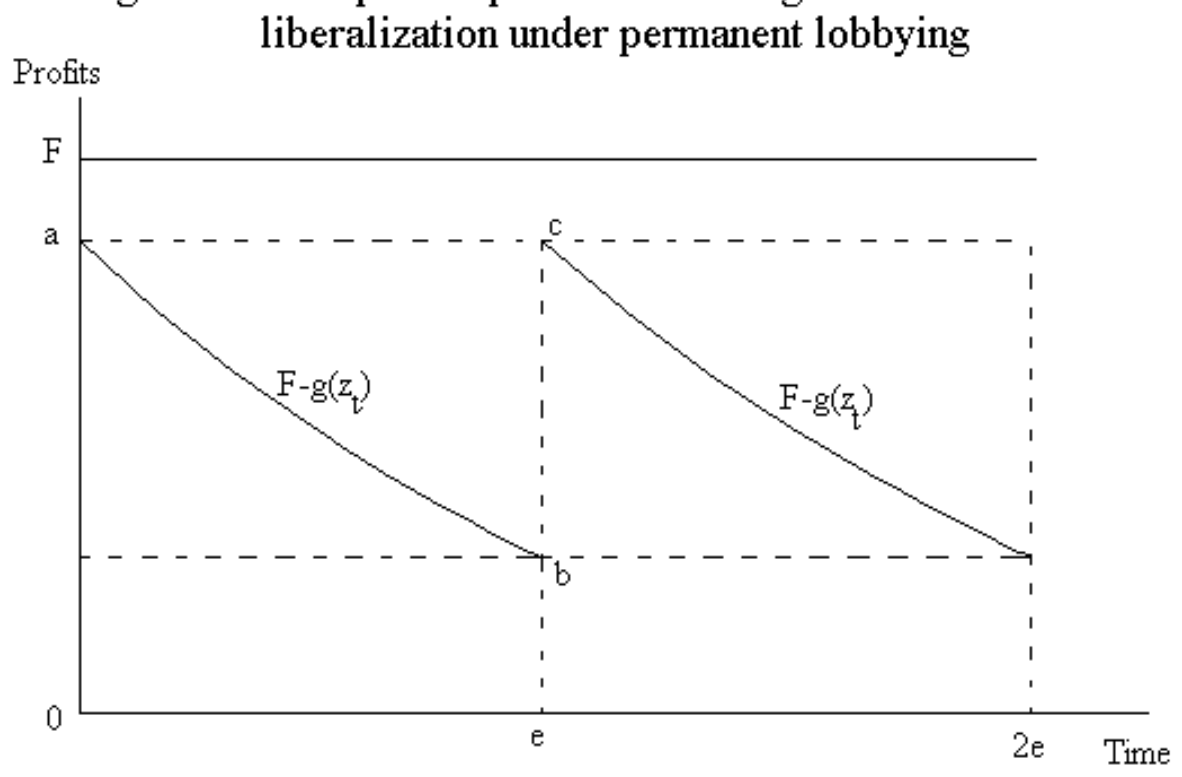

$0 F$ : Profits before contribution; F-g( $\left.z_{t}\right)$ : Profits after contribution; bc: Opportunity cost of imitation; $z_{\mathrm{t}}$ : inverse of quality gap; e, 2e: Timings of imitation and liberalization 
Figure 3: Profits and timing of imitation and lobbying under alternating free trade and lobbying

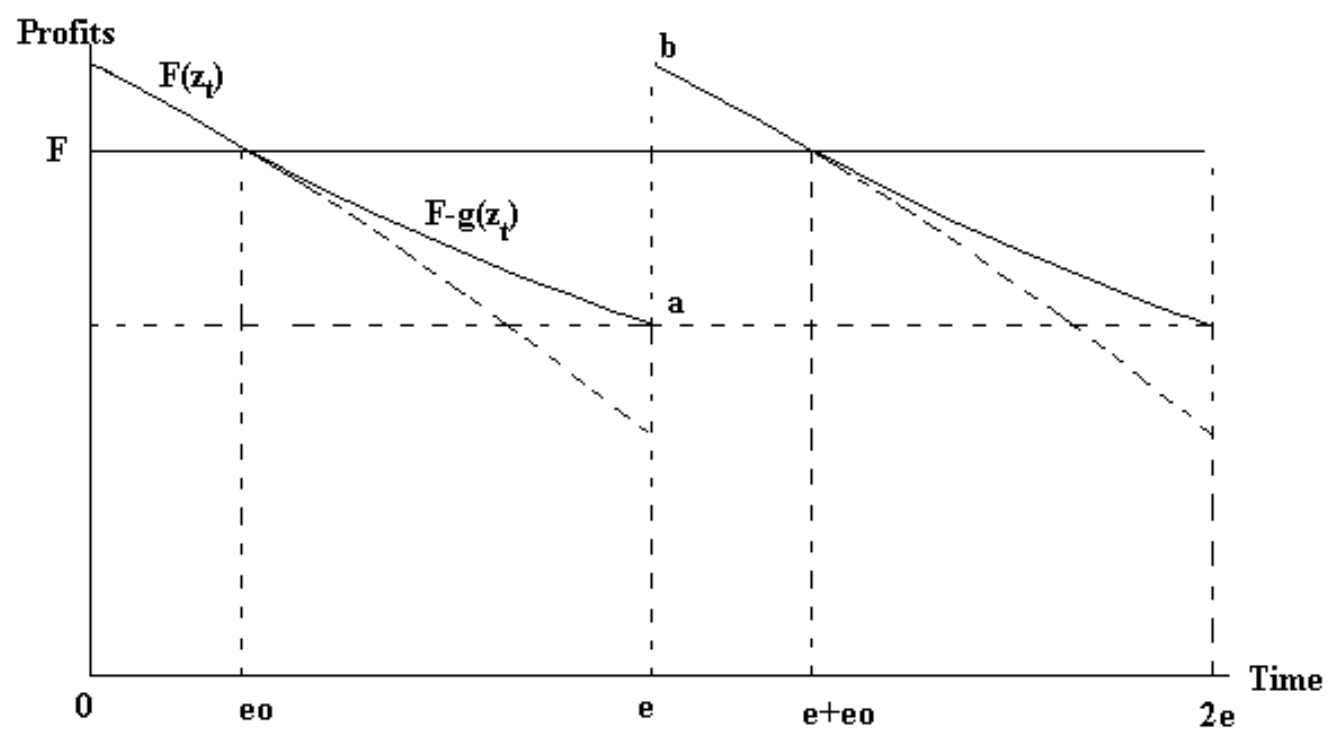

OF: Profits before contribution; F-g(z): Profits after contribution; F(z): Profits under free trade; ab: Opportunity cost of imitation; eo, e+eo: Timings of lobbying initiation; $\mathrm{e}, 2 \mathrm{e}$ : Timings of imitation and liberalization ; $z_{\mathrm{t}}$ : Inverse of the quality gap 


\section{References}

Bhagwati, J. (1978), “Anatomy and Consequences of Exchange Control Regimes,” vol. XI of Foreign Trade Regimes and Economic Development, for the National Bureau of Economic Research, Ballinger: Cambridge.

Brainard, S., and T. Verdier (1994), "Lobbying and Adjustment in Declining Industries," European Economic Review, XXXVIII(3), April, 586-595.

Cassing, J., and A. Hillman (1986), "Shifting Comparative Adjustment and Senescent Industry Collapse," American Economic Review, LXXVI: 516-323.

Clapham, C. (1985), Third World Politics, Madison: University of Wisconsin Press.

Evenson, R., and L. Westphal (1995), “Technological Development and Technology Strategy,” in J. Behrman and T.N. Srinivasan (eds.), Handbook of Development Economics, Volume III, Elsevier Science Publishers.

Fernández, R., and D. Rodrik (1991), "Resistance to Reform: Status Quo Bias in the Presence of Individual-Specific Uncertainty,” American Economic Review, LXXXI: 1146-1155.

Findlay, R. (1991), “The New Political Economy: Its Explanatory Power for LDCs,” in G. Meier (ed.), Politics and Policy Making in Developing Countries, ICS Press, San Francisco, CA.

Findlay, R., and S. Wellisz (1982), "Endogenous Tariffs, the Political Economy of Trade Restrictions, and Welfare," in J. Bhagwati (ed.), Import Competition and Policy

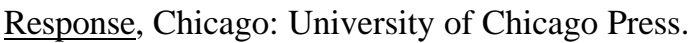

Grossman, G. (1992), “A Model of Quality Competition and Dynamic Comparative Advantage,” in G. Grossman (ed.), Imperfect Competition and International Trade, MIT Press, Cambridge, MA.

Grossman, G., and E. Helpman (1991), Innovation and Growth in the Global Economy, MIT Press, Cambridge, MA.

Grossman, G., and E. Helpman (1994), "Protection for Sale," American Economic Review, LXXXIV: 833-850.

Harrison, A. (1994), "Productivity, Imperfect Competition and Trade Reform: Theory and Evidence," Journal of International Economics, 36:53-73.

Harrison, A. (1996), “Openness and Growth: A Time Series, Cross-Country Analysis for Developing Countries," Journal of Development Economics, 48:419-447.

International Monetary Fund (1994), "International Trade Policies: The Uruguay Round and Beyond Volume II. Background Papers," World Economic and Financial Surveys, International Monetary Fund, Washington, D.C.

Katz, J., M. Gutkowski, M. Rodrigues, and G. Goity (1987), "Productivity and Domestic Technological Search Efforts: The Growth Path of a Rayon Plant in Argentina," in J. Katz (ed.) Technology Generation in Latin American Manufacturing Industries, New York: St. Martin's Press.

Katz, J. (ed) (1987), Technology Generation in Latin American Industries, New York: St. Martin's Press.

Krishna, P., and D. Mitra (1994), “Trade Liberalization, Market Discipline and Productivity 
Growth: New Evidence from India," mimeo, Columbia University.

Krueger, A. (1993), Political Economy of Policy Reform in Developing Countries, The Ohlin Lectures, No. 4. Cambridge and London: MIT Press.

Krueger, A. (1978), "Liberalization Attempts and Consequences," vol. X of Foreign Trade Regimes and Economic Development, for the National Bureau of Economic Research, Ballinger: Cambridge.

Krusell, P., and J. Rios-Rull (1996), "Vested Interests and a Positive Theory of Stagnation and Growth," Review of Economic Studies, 63: 301-331.

Leamer, E. (1996), “In Search of Stolper-Samuelson Effects on U.S. Wages,” NBER Working Paper 5427, January.

Lenway, S., R. Morck, and B. Yeung (1996), “Rent Seeking, Protectionism and Innovation in the American Steel Industry,” The Economic Journal, 106 (March), 410-421.

Little, I., T. Scitovsky, and M. Scott (1970), Industry and Trade in Developing Countries: A Comparative Study, London: Oxford University Press.

Magee, S., W. Brock, and L. Young (1989), Black Hole Tariffs and Endogenous Policy Theory, Cambridge: Cambridge University Press.

Maggi, G., and A. Rodriguez-Clare (1996), "The Value of Trade Agreements in the Presence of Political Pressures," unpublished mimeo.

Matsuyama, K., (1990), "Perfect Equilibria in a Trade Liberalization Game,” American Economic Review, LXXX: 480-492.

Maxwell, P. (1987), “Adequate Technological Strategy in an Imperfect Economic Context: a Case-Study of the Evolution of the Acindar Steelplant in Rosario, Argentina," in J. Katz (ed.) Technology Generation in Latin American Manufacturing Industries, New York: St. Martin's Press.

Mayer, W. (1984), "Endogenous Tariff Formation,” American Economic Review, LXXIV: 97085.

Miyagiwa, K., and Y. Ohno (1995), "Closing the Technology Gap Under Protection,” American Economic Review, LXXXV: 755-770.

Papageorgiu, D., M. Michaely, and A. Choksi (eds.) (1991), Liberalizing Foreign Trade, Volumes 1 and 4, Basil Backwell.

Rama, M. (1993), "Rent Seeking and Economic Growth: A Theoretical Model and Some Empirical Evidence," Journal of Development Economics, 42:33-50.

Reiganum, J. (1989), “The Timing of Innovation: Research, Development, and Diffusion,” in R. Schmalensee and R. Willig (eds.), Handbook of Industrial Organization, Elsevier Science Publishers.

Rodriguez-Clare, A. (1996), “The Role of Trade in Technology Diffusion,” mimeo, University of Chicago.

Rodrik, D. (1994), “The Rush to Free Trade in the Developing World: Why so Late? Why Now? Will it last? in S. Haggard and S. Webb (eds.), Voting for Reform: The Politics of Adjustment in New Democracies, New York: Oxford University Press. 
Sachs, J., and A. Warner (1995), "Economic Reform and the Process of Global Integration," Brookings Papers on Economic Activity, 1, 327-377.

Sheshinski, E. and Y. Weiss (1977), "Inflation and Costs of Price Adjustment," Economic Studies, 44: 287-303. 


\section{APPENDIX A}

\section{Solution to the firm's dynamic optimization problem:}

The firm's objective will be to choose sequences $\left\{t_{\tau}\right\},\left\{T_{\tau}\right\},\left\{q_{\tau}\right\}, \tau=1,2, \ldots$, that maximize

$$
\begin{aligned}
V_{0}=\sum_{\tau=0}^{\infty} & {\left[\int_{t_{\tau}}^{T_{\tau}} F\left[q_{\tau} e^{-\lambda t}\right] e^{-\rho t} d t+\int_{T_{\tau}}^{t_{\tau+1}} F\left[q_{\tau} e^{-\lambda t}\left(1+\delta_{t-t_{\tau}}\right)\right] e^{-\rho t} d t-\beta e^{-\rho t_{\tau+1}}\right.} \\
& \left.-\int_{T_{\tau}}^{t_{\tau+1}} g\left(1+\delta_{t-t_{\tau}}\right) e^{-\rho t} d t\right]
\end{aligned}
$$

where initial quality is assumed to be $q_{0}=1$, and $t_{0}=0$, subject to $q_{\tau} \leq e^{\lambda t_{\tau}}$. The first order conditions for the optimization over $\left\{t_{\tau}\right\},\left\{T_{\tau}\right\}$, and $\left\{q_{\tau}\right\}$ are:

A.1 $\quad \int_{t_{\tau}}^{T_{\tau}} \frac{\partial F\left[q_{\tau} e^{-\lambda t}\right]}{\partial q_{\tau}} e^{-\rho t} d t+\int_{T_{\tau}}^{t_{\tau}+1} \frac{\partial F\left[q_{\tau} e^{-\lambda t}\left(1+\delta_{t-t_{\tau}}\right)\right]}{\partial q_{\tau}} e^{-\rho t} d t=\mu_{\tau} e^{-\rho t_{\tau}}$

A.2 $F\left[q_{\tau} e^{-\lambda t_{\tau}}\right]-F\left[q_{\tau-1} e^{-\lambda t_{\tau}}\left(1+\delta_{t_{\tau}-t_{\tau-1}}\right)\right]+g\left(1+\delta_{t_{\tau}-t_{\tau-1}}\right)-\rho \beta=\mu_{\tau} \lambda e^{\lambda t_{\tau}}$

A.3 $F\left[q_{\tau} e^{-\lambda T_{\tau}}\right]-F\left[q_{\tau} e^{-\lambda T_{\tau}}\left(1+\delta_{T_{\tau}-t_{\tau}}\right)\right]+g\left(1+\delta_{T_{\tau}-t_{\tau}}\right)=0$
A.4 $\quad \mu_{\tau} \geq 0$
$e^{\lambda t_{\tau}}-q_{\tau} \geq 0$
$\mu_{\tau}\left[e^{\lambda t_{\tau}}-q_{\tau}\right]=0$

Determination of $\left\{q_{\tau}\right\}$ : As before, the marginal return from relaxing the quality constraint will be positive, and hence, from A.1 and A.4,

\section{A.5 $q_{\tau}=e^{\lambda t_{\tau}}$}

Determination of $\left\{T_{\tau}\right\}$ : The first order condition for $\left\{T_{\tau}\right\}$, equation A.3, can be reexpressed, substituting for the optimal $\left\{q_{\tau}\right\}$ from A.6, for the equilibrium $\left\{1+\delta_{t-t_{\tau}}\right\}$ from (23), and for the contribution schedule from (24), as

A.6 $\quad s_{x}\left[1-\frac{w e^{\lambda\left(T_{\tau}-t_{\tau}\right)}}{w^{N}}\right]=s_{x}\left[1-\frac{1}{(1+a)}\right]-\frac{s_{x}}{a} \log \left[\frac{(1+a) w e^{\lambda\left(T_{\tau}-t_{\tau}\right)}}{w^{N}}\right]$ 
The length of the free trade sub-interval, $\left\{T_{\tau}-t_{\tau}\right\}$, will be unique (shown below), and will be implicitly determined by equation A.6. Denoting this subinterval by $\varepsilon_{o}$, we can now rewrite A.6 as:

\section{A.7 $\varepsilon_{o}=\lambda^{-1} \log \left[w^{N} /(1+a) w\right]$}

Determination of $\left\{t_{\tau}\right\}$ : The first order condition for $\left\{t_{\tau}\right\}$, equation A.2, can be reexpressed, substituting for $\mu_{\tau}$ from A.1, for the optimal $\left\{q_{\tau}\right\}$ from A.5, for the equilibrium $\left\{1+\delta_{t-t_{\tau}}\right\}$ from (23), and for the contribution schedule from (24), as

A.8 $\frac{1}{(1+a)}-\frac{w}{w^{N}}-\frac{\rho \beta}{s_{x}}+\frac{1}{a}\left[\log \left[\frac{(1+a) w e^{\lambda\left(t_{\tau}-t_{\tau-1}\right)}}{w^{N}}\right]+\frac{1}{1+a}-\frac{w e^{\lambda\left(t_{\tau}-t_{\tau-1}\right)}}{w^{N}}\right]=$

$$
\frac{\lambda}{(\lambda-\rho)} \frac{w}{w^{N}}\left[e^{(\lambda-\rho)\left(T_{\tau}-t_{\tau}\right)}-1\right]+\frac{\lambda}{(1+a) \rho}\left[e^{-\rho\left(T_{\tau}-t_{\tau}\right)}-e^{-\rho\left(t_{\tau}+1^{-} t_{\tau}\right)}\right]
$$

which, denoting $\left\{t_{\tau}-t_{\tau-1}\right\}=\varepsilon,\left\{t_{\tau+1}-t_{\tau}\right\}=\varepsilon^{\prime},\left\{T_{\tau+1}-t_{\tau}\right\}=\varepsilon_{o}{ }^{\prime}$, can be re-written as

$$
\begin{aligned}
\frac{1}{(1+a)}-\frac{w}{w^{N}}- & \frac{\rho \beta}{s_{x}}+\frac{1}{a}\left[\log \left[\frac{(1+a) w e^{\lambda \varepsilon}}{w^{N}}\right]+\frac{1}{1+a}-\frac{w e^{\lambda \varepsilon}}{w^{N}}\right]= \\
& \frac{\lambda}{(\lambda-\rho)} \frac{w}{w^{N}}\left[e^{(\lambda-\rho)\left(\varepsilon_{O}^{\prime}-\varepsilon\right)}-1\right]-\frac{\lambda}{(1+a) \rho}\left[e^{-\rho\left(\varepsilon^{\prime}-\varepsilon\right)}-e^{-\rho\left(\varepsilon_{O}^{\prime}-\varepsilon\right)}\right]
\end{aligned}
$$

The length of the interval during between imitations, will be unique (shown below), and will be implicitly determined by equation A.11, which can thus be re-written as:

A.11 $\frac{1}{(1+a)}-\frac{w}{w^{N}}-\frac{\rho \beta}{s_{x}}+\frac{1}{a}\left[\log \left[\frac{(1+a) w e^{\lambda \varepsilon}}{w^{N}}\right]+\frac{1}{1+a}-\frac{w e^{\lambda \varepsilon}}{w^{N}}\right]=$

$$
\frac{\lambda}{(\lambda-\rho)} \frac{w}{w^{N}}\left[e^{(\lambda-\rho) \varepsilon_{o}}-1\right]-\frac{\lambda}{(1+a) \rho}\left[e^{-\rho \varepsilon}-e^{-\rho \varepsilon_{o}}\right]
$$

Since both $\varepsilon$ and $\varepsilon_{o}$ will be unique, the length of the subinterval during which lobbying prevails, denoted by $\varepsilon_{c}=\left\{t_{\tau+1}-T_{\tau}\right\}$, will also be unique. 


\section{Comparative statics:}

First let us define $H^{\prime}(\varepsilon)=\frac{\lambda}{a}\left[1-\frac{w e^{\lambda \varepsilon}}{w^{N}}+\frac{a}{1+a} e^{-\rho\left(\varepsilon^{\prime}-\varepsilon\right)}\right]>0$. Then,

A.12 $\frac{d \varepsilon}{d \beta}=\frac{a \rho}{s_{x}} H^{\prime}(\varepsilon)^{-1}>0$

$$
\begin{aligned}
& \frac{d \varepsilon}{d a}=\left\{a^{-2} g\left(1+\delta_{\varepsilon}\right)+\left(\lambda /(1+a)^{2} \rho\right)\left[e^{-\rho\left(\varepsilon^{\prime}-\varepsilon\right)}-e^{-\rho\left(\varepsilon_{o}^{\prime}-\varepsilon\right)}\right]\right\} H^{\prime}(\varepsilon)^{-1}>0 \\
& \frac{d \varepsilon}{d\left[w / w^{N}\right]}=\left\{1-\frac{1}{a}\left[\frac{w^{N}}{w}-e^{\lambda \varepsilon}\right]+\frac{\lambda}{\lambda-\rho}\left[e^{(\lambda-\rho) \varepsilon_{o}^{\prime}}-1\right]\right\} H^{\prime}(\varepsilon)^{-1}: \text { ambiguous. } \\
& \frac{d \varepsilon}{d \lambda}=\left\{\frac{\varepsilon}{a}\left[\frac{w e^{\lambda \varepsilon}}{w^{N}}-1\right]-\frac{w}{(\lambda-\rho) w^{N}} K+\frac{e^{\rho \varepsilon}\left(e^{-\rho \varepsilon^{\prime}}-e^{\rho \varepsilon_{o}^{\prime}}\right)}{(1+a) \rho}\right\} H^{\prime}(\varepsilon)^{-1}: \text { ambiguous. } \\
& K=\left[-\rho+e^{(\lambda-\rho)\left(\varepsilon_{o}^{\prime}-\varepsilon\right)}\left(\rho-\lambda\left(\varepsilon_{o}^{\prime}-\varepsilon\right)\right)\right]
\end{aligned}
$$

Determination of $\left\{t_{\tau}\right\}$ when permanent lobbying is optimal:

The first order conditions for $\left\{q_{\tau}\right\}$ and $\left\{t_{\tau}\right\}$, must be re-expressed as

A.1 $\int_{t_{\tau}}^{t_{\tau+1}} \frac{\partial F\left[q_{\tau} e^{-\lambda t}\left(1+\delta_{t-t_{\tau}}\right)\right]}{\partial q_{\tau}} e^{-\rho t} d t=\mu_{\tau} e^{-\rho t_{\tau}}$

\section{A.2'}

$F\left[q_{\tau} e^{-\lambda t_{\tau}}\left(1+\delta_{0}\right)\right]-F\left[q_{\tau-1} e^{-\lambda t_{\tau}}\left(1+\delta_{t_{\tau}-t_{\tau-1}}\right)\right]-g\left(1+\delta_{0}\right)+g\left(1+\delta_{t_{\tau}-t_{\tau-1}}\right)-\rho \beta=\mu_{\tau} \lambda e^{\lambda t}$

A.2' can be re-expressed, substituting for $\mu_{\tau}$ from A.1', the optimal $\left\{q_{\tau}\right\}$ from A.6, the equilibrium $\left\{1+\delta_{t-t_{\tau}}\right\}$ from (23), and the contribution schedule from (24), as

A.13 $\frac{1}{a}\left[\lambda\left(t_{\tau}-t_{\tau-1}\right)+\frac{w}{w^{N}} e^{\lambda\left(t_{\tau}-t_{\tau-1}\right)}\right]-\frac{\rho \beta}{s_{x}}=\frac{\lambda}{(1+a) \rho}\left[1-e^{-\rho\left(t_{\tau+1}-t_{\tau}\right)}\right]$

which, denoting $\left\{t_{\tau}-t_{\tau-1}\right\}=\varepsilon,\left\{t_{\tau+1}-t_{\tau}\right\}=\varepsilon^{\prime}$, can be re-written as 
A.14 $\frac{1}{a}\left[\lambda \varepsilon+\frac{w}{w^{N}} e^{\lambda \varepsilon}\right]-\frac{\rho \beta}{s_{x}}=\frac{\lambda}{(1+a) \rho}\left[1-e^{-\rho\left(\varepsilon^{\prime}-\varepsilon\right)}\right]$

Equation A.14 implicitly defines the length of the interval without adjustment when permanent lobbying is optimal. Also in this case, applying the principle of optimality, the duration of this interval will be constant, and I can thus re-express A.14 as

A.15 $\frac{1}{a}\left[\lambda \varepsilon+\frac{w}{w^{N}} e^{\lambda \varepsilon}\right]-\frac{\rho \beta}{s_{x}}=\frac{\lambda}{(1+a) \rho}\left[1-e^{-\rho \varepsilon}\right]$

Comparative Statics:

First let us define $H^{\prime}(\varepsilon)$ as before. Then,

A.16 $\frac{d \varepsilon}{d \beta}=\frac{\rho}{s_{x}} H^{\prime}(\varepsilon)^{-1}>0$

$$
\begin{aligned}
& \frac{d \varepsilon}{d a}=a^{-1}\left\{\rho \beta / s_{x}+\left(\lambda /(1+a)^{2} \rho\right)\left[1-e^{-\rho\left(\varepsilon^{\prime}-\varepsilon\right)}\right]\right\} H^{\prime}(\varepsilon)^{-1}>0 \\
& \frac{d \varepsilon}{d\left[w / w^{N}\right]}=-\frac{1}{a}\left[1-e^{\lambda \varepsilon}\right] H^{\prime}(\varepsilon)^{-1}<0 \\
& \frac{d \varepsilon}{d \lambda}=\frac{s_{x}}{a}\left[\frac{1}{\rho}-\varepsilon\left[1-e^{-\rho \varepsilon}\right]^{-1}\right] H^{\prime}(\varepsilon)-1: \text { ambiguous sign. }
\end{aligned}
$$

\section{Proof of Propositions 2 and 3 :}

For any solution $\left\{t_{\tau}^{*}\right\},\left\{T_{\tau}^{*}\right\},\left\{q_{\tau}^{*}\right\}$, there exists a unique pair $\varepsilon_{o}, \varepsilon$, such that $T_{\tau}^{*}=t_{\tau}^{*}+\varepsilon_{o}, t_{\tau+1}^{*}=t_{\tau}^{*}+\varepsilon$ and $q_{\tau+1}^{*}=q_{\tau}^{*} e^{\lambda \varepsilon}$.

Proof. As in Sheshinski and Weiss (1977), by the principle of optimality, if $\left\{t_{\tau}^{*}\right\},\left\{T_{\tau}^{*}\right\},\left\{q_{\tau}^{*}\right\}$, maximize $V_{0}$, they also maximize the present discounted value of profits at $t_{1}{ }^{*}, t_{2}{ }^{*}, \ldots$, and so on, denoted by $V_{1}, V_{2}, \ldots$. Specifically,

A.17 $\quad V_{1}=\sum_{\tau=1}^{\infty}\left[\int_{t_{\tau}}^{T_{\tau}} F\left[q_{\tau} e^{-\lambda t}\right] e^{-\rho\left(t-t_{1}^{*}\right)} d t+\int_{T_{\tau}}^{t_{\tau+1}} F\left[q_{\tau} e^{-\lambda t}\left(1+\delta_{t-t_{\tau}}\right)\right] e^{-\rho\left(t-t_{1}^{*}\right)} d t\right.$ 


$$
\left.\left.-\beta e^{-\rho\left(t_{\tau+1}-t_{1}^{*}\right)}-\int_{T_{\tau}}^{t_{\tau+1}} g\left(1+\delta_{t-t_{\tau}}\right)\right] e^{-\rho\left(t-t_{1}^{*}\right)} d t\right]
$$

A.18 $V_{2}=\sum_{\tau=2}^{\infty}\left[\int_{t_{\tau}}^{T_{\tau}} F\left[q_{\tau} e^{-\lambda t}\right] e^{-\rho\left(t-t_{2}^{*}\right)} d t+\int_{T_{\tau}}^{t_{\tau+1}} F\left[q_{\tau} e^{-\lambda t}\left(1+\delta_{t-t_{\tau}}\right)\right] e^{-\rho\left(t-t_{2}^{*}\right)} d t\right.$

$$
\left.\left.-\beta e^{-\rho\left(t_{\tau+1}-t_{2}^{*}\right)}-\int_{T_{\tau}}^{t_{\tau+1}} g\left(1+\delta_{t-t_{\tau}}\right)\right] e^{-\rho\left(t-t_{2}^{*}\right)} d t\right]
$$

A.19 $V_{2}=\sum_{\tau=1}^{\infty}\left[\int_{t_{\tau+1}}^{T_{\tau+1}} F\left[q_{\tau+1} e^{-\lambda t}\right] e^{-\rho\left(t-t_{2}^{*}\right)} d t+\int_{T_{\tau+1}}^{t_{\tau+2}} F\left[q_{\tau+1} e^{-\lambda t}\left(1+\delta_{t-t_{\tau+1}}\right)\right] e^{-\rho\left(t-t_{2}^{*}\right)} d t\right.$

$$
\left.\left.-\beta e^{-\rho\left(t_{\tau+2}-t_{2}^{*}\right)}-\int_{T_{\tau+1}}^{t_{\tau+2}} g\left(1+\delta_{t-t_{\tau+1}}\right)\right] e^{-\rho\left(t-t_{2}^{*}\right)} d t\right]
$$

Using the transformation $u=t-t_{1}{ }^{*}$, rewrite A.17 as:

$$
\begin{gathered}
V_{1}=\sum_{\tau=1}^{\infty}\left[\int_{t_{\tau}-t_{1}^{*}}^{T_{\tau}-t_{1}^{*}} F\left[q_{\tau} e^{-\lambda t_{1}^{*}} e^{-\lambda u}\right] e^{-\rho u} d u+\int_{T_{\tau}-t_{1}^{*}}^{t_{\tau+1}-t_{1}^{*}} F\left[q_{\tau} e^{-\lambda t_{1}^{*}} e^{-\lambda u}\left(1+\delta_{u+t_{1}^{*}-t_{\tau}}\right)\right] e^{-\rho u} d u\right. \\
\left.\left.-\beta e^{-\rho\left(t_{\tau+1}-t_{1}^{*}\right)}-\int_{T_{\tau}-t_{1}^{*}}^{t_{\tau+1}-t_{1}^{*}} g\left(1+\delta_{u+t_{1}^{*}-t_{\tau}}\right)\right] e^{-\rho u} d u\right]
\end{gathered}
$$

Similarly, using $u=t-t_{2}{ }^{*}$, rewrite A.19 as:

$$
\begin{aligned}
V_{2}=\sum_{\tau=1}^{\infty}\left[\int_{t_{\tau+1}-t_{2}^{*}}^{T_{\tau+1}-t_{2}^{*}} F\left[q_{\tau+1} e^{-\lambda t_{2}^{*}} e^{-\lambda u}\right] e^{-\rho u} d u+\int_{T_{\tau+1}-t_{2}^{*}}^{t_{\tau+2}-t_{2}^{*}} F\left[q_{\tau+1} e^{-\lambda t_{2}^{*}} e^{-\lambda u}\left(1+\delta_{u+t_{2}-t_{\tau+1}}\right)\right] e^{-\rho u} d u\right. \\
\\
\left.\left.\quad-\beta e^{-\rho\left(t_{\tau+2}-t_{2}^{*}\right)}-\int_{T_{\tau+1}-t_{2}^{*}}^{t_{\tau+2}-t_{2}^{*}} g\left(1+\delta_{u+t_{2}^{*}-t_{\tau+1}}\right)\right] e^{-\rho u} d u\right]
\end{aligned}
$$

The variables to be determined in $V_{1}$ are

$$
\begin{aligned}
& \left\{t_{\tau}-t_{1}^{*}\right\}=\left\{0, t_{2}-t_{1}^{*}, t_{3}-t_{1}^{*}, \ldots\right\}, \quad\left\{T_{\tau}-t_{1}^{*}\right\}=\left\{T_{1}-t_{1}^{*}, T_{2}-t_{1}^{*}, T_{3}-t_{1}^{*}, \ldots\right\}, \\
& \left\{q_{\tau} e^{-\lambda t_{1}^{*}}\right\}=\left\{q_{1}^{*} e^{-\lambda t_{1}^{*}}, q_{2} e^{-\lambda t_{1}^{*}}, \ldots\right\}
\end{aligned}
$$

In $V_{2}$, the variables to be determined are: 


$$
\begin{aligned}
& \left\{t_{\tau+1}-t_{2}^{*}\right\}=\left\{0, t_{3}-t_{2}^{*}, t_{4}-t_{2}^{*}, \ldots\right\}, \quad\left\{T_{\tau+1}-t_{2}^{*}\right\}=\left\{T_{2}-t_{2}^{*}, T_{3}-t_{2}^{*}, T_{4}-t_{2}^{*}, \ldots\right\} \\
& \left\{q_{\tau+1} e^{-\lambda t_{2}^{*}}\right\}=\left\{q_{2}^{*} e^{-\lambda t_{2}^{*}}, q_{3} e^{-\lambda t_{2}^{*}}, \ldots\right\}
\end{aligned}
$$

The functions $V_{1}$ and $V_{2}$ are identical in the corresponding variables. Hence,

$t_{2}^{*}-t_{1}^{*}=t_{3}^{*}-t_{2}^{*}=\ldots=\varepsilon$ and $T_{1}^{*}-t_{1}^{*}=T_{2}^{*}-t_{2}^{*}=\ldots=\varepsilon_{o}$,

$q_{1}^{*} e^{-\lambda t_{1}^{*}}=q_{2}^{*} e^{-\lambda t_{2}^{*}}=\ldots$ or $q_{2}^{*}=q_{1}^{*} e^{\lambda\left(t_{2}^{*}-t_{1}^{*}\right)}=q_{1}^{*} e^{\lambda \varepsilon}$

\section{Proof of Proposition 4:}

Identical to the proof of Propositions 2 and 3, making $\varepsilon_{o}=0$. 


\section{LOBBYING, INNOVATION, AND PROTECTIONIST CYCLES}

Available upon request.

\section{APPENDIX B}

\section{Solution to the consumers' optimization problem:}

Consumers will optimize by choosing an optimal time pattern for spending and by allocating spending optimally at each point in time. Given prices $p_{m}(j)$ for the differentiated goods, $p_{y t}$ for the homogeneous good, and given expenditure $E(t)=\int_{0}^{1}\left[\sum_{m} p_{m t}(j) x_{m t}(j)\right] d j+p_{y t} y_{t}$, consumers maximize instantaneous utility by allocating a share $s_{x}$ of spending to high-tech goods and spreading this share evenly across product types. Substituting into (1), we get the indirect utility function $U_{0}=\int_{0}^{\infty}\left\{\log E(t)-s_{x} \int_{0}^{1} \log \left[p_{t}(j) / q_{t}(j)\right] d j-\left(1-s_{x}\right) \log p_{y t}\right\} e^{-\rho t} d t$, where $p_{t}(j) / q_{t}(j)$ denotes the lowest quality-adjusted price for each $j$, which is maximized over $E(t)$. The dynamic budget constraint is given by $\dot{B}(t)=w(t)+r(t) B(t)-E(t)$, were $B(t)$ is the value of financial asset holdings at time $t, w(t)$ denotes wage income, and $r(t)$ is the interest rate. I assume here that there exists perfect international capital mobility, with the domestic rate of time preference being equal to the given international interest rate. Nominal expenditure will thus be constant, and can be normalized to one. The inclusion of entrepreneurs as consumers would not change the results regarding the time pattern of spending, since it would also be optimal for them to smooth consumption expenditure over time. 
Solution to the firm's dynamic optimization problem:

The firm's objective will be to choose sequences $\left\{t_{\tau}\right\},\left\{q_{\tau}\right\}, \tau=1,2, \ldots$ that maximize $V_{0}=\sum_{\tau=0}^{\infty}\left[\int_{t_{\tau}}^{t_{\tau+1}} F\left[q_{\tau} e^{-\lambda t}\right] e^{-\rho t} d t-\beta e^{-\rho t_{\tau+1}}\right]$, where initial quality is assumed to be $q_{0}=1$, and $t_{0}=0$, subject to $q_{\tau} \leq e^{\lambda t_{\tau}} \cdot{ }^{46}$ The Lagrangean for this problem is:

B.1 $\mathfrak{I}=\sum_{\tau=0}^{\infty}\left[\int_{t_{\tau}}^{t_{\tau+1}} F\left[q_{\tau} e^{-\lambda t}\right] e^{-\rho t} d t-\beta e^{-\rho t_{\tau+1}}+\mu_{\tau} e^{-\rho t}\left[e^{\lambda t_{\tau}}-q_{\tau}\right]\right]$

The first order conditions for the optimization over $\left\{q_{\tau}\right\}$ and $\left\{t_{\tau}\right\}$ are:

B. $2 \int_{t_{\tau}}^{t_{\tau+1}} \frac{\partial F\left[q_{\tau} e^{-\lambda t}\right]}{\partial q_{\tau}} e^{-\rho t} d t=\mu_{\tau} e^{-\rho t_{\tau}}$

B.3 $F\left[q_{\tau} e^{-\lambda t_{\tau}}\right]-F\left[q_{\tau-1} e^{-\lambda t_{\tau}}\right]-\rho \beta=\mu_{\tau} \lambda e^{\lambda t_{\tau}}$
B.4 $\mu_{\tau} \geq 0$
$e^{\lambda t_{\tau}}-q_{\tau} \geq 0$
$\mu_{\tau}\left[e^{\lambda t_{\tau}}-q_{\tau}\right]=0$

Determination of $\left\{q_{\imath}\right\}$ : Equation B.2 and the fact that $F^{\prime}(z)>0$ for all $z$ imply that $\mu>0$ (the firm would be better off if it could adjust quality beyond the foreign quality level). This condition and the slack condition, equation B.4 in turn imply that

B.5 $q_{\tau}=e^{\lambda t_{\tau}}$

Determination of $\left\{t_{\tau}\right\}$ : The first order condition for $\left\{t_{\tau}\right\}$, equation B.3, can be reexpressed, substituting for $\mu_{\tau}$ from B.2, and for the optimal $\left\{q_{\tau}\right\}$ from B.5 as

B.6 $\left[e^{\lambda\left(t_{\tau}-t_{\tau-1}\right)}-1\right]-\frac{\lambda}{\lambda-\rho}\left[e^{(\lambda-\rho)\left(t_{\tau+1}-t_{\tau}\right)}-1\right]=\frac{w^{N}}{s_{x} w} \rho \beta$

which, substituting $t_{\tau}-t_{\tau-1}$ by $\varepsilon$, and $t_{\tau+1}-t_{\tau}$ by $\varepsilon^{\prime}$ can be re-written as:

B.7 $\left[e^{\lambda \varepsilon}-1\right]-\frac{\lambda}{\lambda-\rho}\left[e^{(\lambda-\rho)\left(\varepsilon^{\prime}-\varepsilon\right)}-1\right]=\frac{w^{N}}{s_{x} w} \rho \beta$ 


\section{Proof of Proposition 1:}

Uniqueness of $t_{\tau}-t_{\tau-1}:$ The problem faced by the domestic monopolist here is very similar to the one analyzed by Sheshinski and Weiss (1977). As in their case, for any solution $\left\{t_{\tau}^{*}\right\},\left\{q_{\tau}^{*}\right\}$, there exists a unique $\varepsilon$ such that $t_{\tau+1}^{*}=t_{\tau}^{*}+\varepsilon$ and $q_{\tau+1}^{*}=q_{\tau}^{*} e^{\lambda \varepsilon}$.

Proof. As in Sheshinski and Weiss (1977), by the principle of optimality, if $\left\{t_{\tau}^{*}\right\},\left\{q_{\tau}^{*}\right\}$, maximize $V_{0}$, they also maximize the present discounted value of profits at $t_{1}{ }^{*}, t_{2}{ }^{*}, \ldots$, and so on, denoted by $V_{1}, V_{2}, \ldots$. Specifically,

B.8 $\quad V_{1}=\sum_{\tau=1}^{\infty}\left[\int_{t_{\tau}}^{t_{\tau+1}} F\left(q_{\tau} e^{-\lambda t}\right) e^{-\rho\left(t-t_{1}^{*}\right)} d t-\beta e^{-\rho\left(t_{\tau+1}-t_{1}^{*}\right)}\right]$

B.9 $\quad V_{2}=\sum_{\tau=2}^{\infty}\left[\int_{t_{\tau}}^{t_{\tau+1}} F\left(q_{\tau} e^{-\lambda t}\right) e^{-\rho\left(t-t_{2}^{*}\right)} d t-\beta e^{-\rho\left(t_{\tau+1}-t_{2}^{*}\right)}\right]$

B.10 $V_{2}=\sum_{\tau=1}^{\infty}\left[\int_{t_{\tau}}^{t_{\tau+1}} F\left(q_{\tau+1} e^{-\lambda t}\right) e^{-\rho\left(t-t_{2}^{*}\right)} d t-\beta e^{-\rho\left(t_{\tau+2}-t_{2}^{*}\right)}\right]$

Using the transformation $u=t-t_{1} *$, rewrite B.8

B.11 $V_{1}=\sum_{\tau=1}^{\infty}\left[\int_{t_{\tau}-t_{1}^{*}}^{t_{\tau+1}-t_{1}^{*}} F\left(q_{\tau} e^{-\lambda t_{1}^{*}} e^{-\lambda u}\right) e^{-\rho u} d u-\beta e^{-\rho\left(t_{\tau+1}-t_{1}^{*}\right)}\right]$

Similarly, using $u=t-t_{2}{ }^{*}$, rewrite B.10 as

B.12 $V_{2}=\sum_{\tau=1}^{\infty}\left[\int_{t_{\tau+1}-t_{2}^{*}}^{t_{\tau+2}-t_{2}^{*}} F\left(q_{\tau+1} e^{-\lambda t_{2}^{*}} e^{-\lambda u}\right) e^{-\rho u} d u-\beta e^{-\rho\left(t_{\tau+2}-t_{2}^{*}\right)}\right]$

The variables to be determined in $V_{1}$ are

$$
\left\{t_{\tau}-t_{1}^{*}\right\}=\left\{0, t_{2}-t_{1}^{*}, t_{3}-t_{1}^{*}, \ldots\right\}, \text { and }\left\{q_{\tau} e^{-\lambda t_{1}^{*}}\right\}=\left\{q_{1}^{*} e^{-\lambda t_{1}^{*}}, q_{2} e^{-\lambda t_{1}^{*}}, \ldots\right\}
$$

In $V_{2}$, the variables to be determined are:

$$
\left\{t_{\tau+1}-t_{2}^{*}\right\}=\left\{0, t_{3}-t_{2}^{*}, t_{4}-t_{2}^{*}, \ldots\right\}, \text { and }\left\{q_{\tau+1} e^{-\lambda t_{2}^{*}}\right\}=\left\{q_{2}^{*} e^{-\lambda t_{2}^{*}}, q_{3} e^{-\lambda t_{2}^{*}}, \ldots\right\}
$$

The functions $V_{1}$ and $V_{2}$ are identical in the corresponding variables. Hence,

$t_{2}^{*}-t_{1}^{*}=t_{3}^{*}-t_{2}^{*}=\ldots=\varepsilon \quad$ and 
$q_{1}^{*} e^{-\lambda t_{1}^{*}}=q_{2}^{*} e^{-\lambda t_{2}^{*}}=\ldots \quad$ or $\quad q_{2}^{*}=q_{1}^{*} e^{\lambda\left(t_{2}^{*}-t_{1}^{*}\right)}=q_{1}^{*} e^{\lambda \varepsilon}$

Therefore, we can re-express B.7 as:

B.13 $\left[e^{\lambda \varepsilon}-1\right]-\frac{\lambda}{\lambda-\rho}\left[e^{(\lambda-\rho) \varepsilon}-1\right]=\frac{w^{N}}{s_{x} w} \rho \beta$

\section{Comparative statics:}

First let us define $H^{\prime}(\varepsilon)=\lambda\left[e^{\lambda \varepsilon}+e^{(\lambda-\rho)\left(\varepsilon^{\prime}-\varepsilon\right)}\right]$. Then the effects of changes in wage differentials, in adjustment costs, and in foreign quality growth are respectively given by:

B.14

$$
\begin{aligned}
& \frac{\partial \varepsilon}{\partial\left(w / w^{N}\right)}=-\left[\frac{w^{N}}{w}\right]^{2} \frac{\rho \beta}{s_{x}} H^{\prime}(\varepsilon)^{-1}<0 \\
& \frac{\partial \varepsilon}{\partial \beta}=\frac{\rho w^{N}}{s_{x} w} H^{\prime}(\varepsilon)^{-1}>0 \\
& \frac{d \varepsilon}{d \lambda}=\left[-\varepsilon e^{\lambda \varepsilon}-\frac{\rho}{(\lambda-\rho)^{2}}\left[e^{(\lambda-\rho)\left(\varepsilon^{\prime}-\varepsilon\right)}-1\right]+\lambda\left(\varepsilon^{\prime}-\varepsilon\right) e^{(\lambda-\rho)\left(\varepsilon^{\prime}-\varepsilon\right)}\right] H^{\prime}(\varepsilon)^{-1}:
\end{aligned}
$$

ambiguous

\footnotetext{
${ }^{1}$ For a thorough analysis of these recent reforms see Rodrik (1994), and Sachs and Warner (1995).

${ }^{2}$ For a description of these episodes see Papageorgiu et al (1991), and Sachs and Warner (1995).

${ }^{3}$ For the episodes of partial reversal see International Monetary Fund (1994).

${ }^{4}$ The cycles analyzed here refer to a drastic overhaul of the protectionist apparatus and its subsequent re-building, and should be distinguished from the cycles identified by Bhagwati (1978) and Krueger (1978), who detected that several developing countries recurrently imposed and removed in an alternating way compensatory import surcharges and export subsidies in response to the overvaluation and subsequent devaluation of the exchange rate, while imports remained severely restricted by quantitative restrictions.

${ }^{5}$ This intuition is well captured in the following quotation from Leamer (1996), pp 2-3: "The view offered here is that at the end of World War II countries sorted themselves into two different groups. Europe and Japan and the Asian NICs chose economic integration with the United States. But most of the rest of the world opted for inward looking isolationist policies. Those that chose integration experienced a period of technological backwardness, but the technological lead that the US enjoyed in the 1960's vis-a-vis the integrated economies dissipated rapidly in the 70s even as the gap increased vis-a-vis the isolated countries. Economic isolationism eventually collapsed as this technological gap became more and more intolerable".

${ }^{6}$ Closed trade policies have been found to negatively affect technological upgrading (Little et al, 1970; Katz 1987), productivity growth (Harrison, 1994; Krishna and Mitra, 1994), and growth directly and through investment (Sachs and Warner, 1995; Harrison, 1996). Protection resulting from interest
} 
group lobbying has been found to reward poor performance and to discourage innovation (Lenway et al, 1996), and to harm growth (Rama, 1993). Finally, while the past temporary liberalizations were accompanied by high growth, the subsequent closures witnessed poor growth performances (Sachs and Warner, 1995).

${ }^{7}$ See Evenson and Westphal (1994).

${ }^{8}$ See Maxwell (1987). Further support comes from the study of the technological behavior of a rayon manufacturer in Argentina: during the initial 12-year period during which the company enjoyed the status of a protected monopolist no innovations were introduced; however, during the subsequent period when it faced the competitive pressure of new entrants it concentrated on introducing quality improvements and on reducing costs. See Katz et al (1987).

${ }^{9}$ See Rodrik (1994).

${ }^{10}$ See Bagwell and Staiger (1996).

${ }^{11}$ For instance consider the case of Uruguay, where the average import tariff increased steadily since the end of World War II until reaching a level of $452.4 \%$ in 1974, and then it was slashed down to $69.5 \%$ in just one year (Favaro and Spiller, 1991).

${ }^{12}$ See Findlay and Wellisz (1982), Mayer (1984), Brock et al (1989), and Grossman and Helpman (1994).

${ }^{13}$ Some pioneering work in this area has been done by Fernandez and Rodrik (1991), Brainard and Verdier (1994), and Maggi and Rodriguez-Clare (1996).

${ }^{14}$ See Krueger (1993).

${ }^{15}$ See Krusell and Rios-Rull (1996).

${ }^{16}$ See Cassing and Hillman (1986), and Brainard and Verdier (1994).

${ }^{17}$ See Miyagiwa and Ohno (1995), and Matsuyama (1990).

${ }^{18}$ This assumption of only one domestic firm per product line can be justified by barriers to entry, private product specific knowledge, fixed costs of entry with a continuum of goods, etc. For instance, in the case of Uruguay during the pre-1974 period of high protection to the manufacturing industry, incumbent firms had preferential access to import quotas of intermediate inputs (Favaro and Spiller, 1991).

${ }^{19}$ The formal solution for the intertemporal optimization problem and for the optimal allocation of expenditure at each time is presented in Appendix B, available from the author upon request.

${ }^{20}$ The implicit assumption is that Northern workers are more productive in the homogenous good sector.

${ }^{21}$ This result does not hinge on the demand function used here. It is robust to more general specifications, subject to the constraint that the monopoly price is higher than the limit price at any quality gap.

${ }_{22}$ The Southern economy is assumed to be small, in the sense that domestic firms do not possess the capacity to export to world markets, and that the domestic market is marginal to foreign producers. Therefore, the actions of the domestic firms do not affect the innovation decisions by the Northern firms.

${ }^{23}$ See Rodriguez-Clare (1996). The results in this section could also be attained by assuming that imitation entails both a fixed cost and a variable cost, assuming that the marginal cost single crosses the benefits from adjustment. It is the presence of a fixed cost element that is required to obtain the result. Additionally it could be argued that the verified importance of the spillovers from Northern innovations on the effectiveness of inventive activity in developing economies (Evenson and Westphal, 1994) makes the costs of imitation grow at a much lower rate than the technology gap, thus making these costs look as if they were "fixed" with respect to the size of the quality gap. The mechanism presented here is also consistent with the models of diffusion of innovation, which link the timing of the adoption of new inventions to the costs of adoption, the adoption by competitors, the expected benefits, and the expectation of the introduction of new inventions (Reiganum, 1989; Evenson and Westphal, 1994).

${ }^{24}$ The problem faced by the domestic producer is similar to that analyzed by Sheshinski and Weiss (1977) of a monopolist that faces a fixed real charge to adjust nominal prices in response to a perfectly anticipated deterministic rate of inflation.

${ }^{25}$ The cyclical pattern of quality adjustments could also be attained by assuming that imitation entails both a fixed cost and a variable cost, as long as the marginal cost of imitation single crosses the benefits from adjustment at a point where profits are non-negative. It is the presence of fixed costs that is required to introduce the value of waiting for the imitation. 
${ }^{26}$ The growth rate of the consumption index is given by $\hat{D}(t)=d s_{x} \int_{0}^{1} \log \left[q_{t}(j) x_{t}(j)\right] d j=s_{x} \int_{0}^{1} \lambda(j) d j$.

${ }^{27}$ This is because wages are fixed and that the expenditure share devoted to the consumption of each good is constant, and is thus unaffected by changes in the prices of the other goods.

${ }_{28}$ The lobbying process is modeled in a similar fashion by Brainard and Verdier (1994).

${ }^{29}$ Tariffs are lobbied upon continuously to avoid problems of time consistency. If the government and the firm negotiated a permanent tariff or a sequence of tariffs at time zero, it would pay to the government to implement the tariff, and then to eliminate it once it has collected the contribution.

${ }^{30}$ This approach is similar to the one used by Brainard and Verdier (1994), where both tariff determination and industry adjustment are continuously done, and where at each time the firm first chooses the level of adjustment and the contribution schedule simultaneously in anticipation of the government's response, and then the government sets the tariff.

${ }^{31}$ See Clapham (1985), Findlay (1991), Krueger (1993). An accurate portrayal of this kind of ruler and of the constraints that it faces is presented in Findlay (1991), p. 19: "The pervasiveness of the state in the economy and society at large, and the extent and persistence of economic controls and regulations, can be seen as maximizing the resources with which the neopatrimonial ruler can reward himself and his followers. ... The more successful the neopatrimonial state is in its predatory exaction on society, however, the less legitimate the regime is in the eyes of the people, since the more blatant is the violation of the publicly proclaimed rational-legal norms."

${ }^{32}$ See Grossman and Helpman (1994).

${ }^{33}$ The result that the equilibrium tariffs are increasing over time to off-set to some extent the widening quality gap can also be attained in a more general framework under the general condition that the marginal benefit of a tariff increases with the size of the quality gap, which is satisfied here.

${ }^{34}$ When the economy reaches the point where the quality gap is such that the domestic producer would be displaced under free trade, profits under free trade would be nil, and the welfare losses from protection would be given by the losses of consumer surplus. Without protection, the consumer surplus remains constant over time after this point is reached, as the quality adjusted price charged by the foreign producer is constant. Since the equilibrium tariffs lead to a constant price, welfare losses from tariffs will be constant after this point, and so will be the contributions. This happens when $t \geq t_{\tau}$ $+(1 / \lambda) \log \left(w^{N} / w\right)$. In this case, contributions in equilibrium are given by $\left(s_{x} / a\right)[\log (1+a)-a /(1+a)]$.

${ }^{35}$ In the model it is assumed that the government does not implement any policy in the absence of contributions. When participating in the game, the resulting equilibrium tariffs have two components: $\left(w / w^{N}\right)$, which is an import subsidy that makes price be equal to marginal cost (optimal static taxation of a monopoly), and $(1+a) \exp \left(\lambda\left(t-t_{\tau}\right)\right)$, which is the contribution induced price increase. When the preferences for contributions are low, at low levels of the quality gap the subsidy component is larger and it is thus not profitable for the firm to involve the government in the contribution game.

${ }^{36}$ In a general framework the requirement for the existence of cycles is that the profits after contribution are declining over time, and at a faster rate than the increase in the costs of imitation. Local truthfulness of the contribution schedules (see Grossman and Helpman, 1994) guarantees that the profits after contribution will decrease over time. The speed at which the profits after contribution decline will depend positively on the marginal change in profits as result of an increase in the quality gap, and on the rate of growth of foreign quality.

${ }^{37}$ For certain parameter values the firm may find it profitable to continue lobbying beyond the quality gap at which it would have been displaced from the market under free trade. At this point, contributions and thus profits after contribution would become constant. Nevertheless, the decline in the marginal value of relaxing the quality constraint by postponing adjustment would still lead to make it optimal to adjust quality at some point. However, for certain parameter values, in particular for relatively large costs of imitation, it may be the case that the benefits of postponing adjustment are always larger and the firm would never adjust. But the size of the costs of imitation has to have an upper bound in any case for the firm to be able to compete under free trade.

${ }^{38}$ Losses of competitiveness will decrease both the profits after the adjustment and the net benefits from lobbying before the adjustment, while increases in $\lambda$ will reduce the net benefits from lobbying before the adjustment. Both changes will increase the positive impact of a delay in imitation on the shadow value of the quality constraint. The net effect is ambiguous. 
${ }^{39}$ A loss of competitiveness will have an ambiguous effect because the negative effect on the net benefits from lobbying is countervailed by the fall in profits under free trade (both at the onset and at the end of the protectionist interval) and by the increase in the shadow value of the quality constraint. ${ }^{40}$ In this case, the first order condition for $\left\{t_{\tau}\right\}$ must be modified to reflect the fact that profits after imitation will be given by $F\left[q_{\tau} e^{-\lambda t_{\tau}}\left(1+\delta_{0}\right)\right]-g\left(1+\delta_{0}\right)$.

${ }^{41} \mathrm{An}$ increase in $\lambda$ will increase both the rate at which welfare losses and contributions are growing over time and the marginal return from relaxing the quality constraint, with an ambiguous effect on $\varepsilon$. ${ }^{42}$ The contribution to the increase of the consumption index will be given by $s_{x}\left\{\lambda \varepsilon+\log \left[(1+a) w / w^{N}\right]\right\}$. ${ }^{43}$ The contribution to the increase of the consumption index will be given by $s_{x} \lambda \varepsilon$.

${ }^{44}$ A relevant example is provided by the Brazilian automobile industry: in mid-1995 tariffs on car imports were raised from $20 \%$ to $70 \%$, and import quotas were reinstated; such measures were justified by Brazilian authorities on the ground of Balance of Payments problems, but were actually implemented in response to sector-specific protectionist pressures. As the WTO argued, this was the only industry to be granted extra protection, when BOP problems would more likely lead to restrict imports across the board. Even when disallowed to introduce the quotas, the Brazilian authorities stated that they would seek every other possible means to protect national industry from the threat of foreign imports.

${ }^{45}$ These stabilization plans have usually included big devaluations, which increase domestic "competitiveness" by reducing relative domestic costs of productions. In this model, a devaluation could be captured as an exogenous decrease in domestic costs of production, which would lead to a "liberalization" through lower equilibrium tariffs. However, this "liberalization" would not be accompanied by a catch-up, because the increase in competitiveness would allow to postpone adjustment, as suggested by the comparative statics exercises.

${ }^{46}$ Note that $\arg \max F(z)=1$. Therefore, to ensure that $V_{0} \geq 0$ at the optimum, the adjustment costs $z$ must be small relative to $F(1)$. 